\title{
Hearing in Butterflies: Neurophysiological Characterization of the Auditory Afferents in Morpho peleides (Nymphalidae)
}

\author{
By \\ Andrew Mikhail
}

A dissertation submitted to the Faculty of Graduate Studies and Research in partial fulfillment of the requirements for the degree of Master of Science in Biology

Carleton University
Ottawa, Ontario

(C) 2014 Andrew Mikhail 


\begin{abstract}
Many butterflies have well developed tympanal ears on their wings but little is known about what they are capable of hearing in their natural environments. The tympanal ear of many butterflies, including Morpho peleides, comprises an outer membrane and a conspicuous inner dome (tholus), both of which are innervated by two separate auditory nerve branches (NII and NIII) and their respective sensory organs. Using extracellular neurophysiological recordings, I explored how this morphology contributes to mechanical sound frequency and amplitude discrimination. I also show that the auditory nerves of $M$. peleides responded to playbacks of the broadband cyclic sounds produced passively during flight of blue jays (Cyanocitta cristata), as well as to the low frequency vocalizations of one of its main avian predators, the rufous-tailed jacamar (Galbula ruficauda), providing further evidence that butterflies and possibly other diurnal insects could be using their sense of hearing to detect and avoid avian predators.
\end{abstract}




\section{Acknowledgments}

Special thanks to my supervisor Dr. Jayne Yack who was always supportive from day one of my graduate studies. Dr. Yack's constant encouragement and enthusiasm is the reason I spent so many hours in the dark basement laboratory of the Nesbitt building. Despite her busy schedule, she always seemed to find time to meet with me, and she encouraged me to publish and present my research at conferences, both locally and internationally. My co-supervisor Dr. John Lewis has been instrumental in the completion of this research. His expertise with data analysis and his knowledge of MATLAB was truly invaluable. I'd also like to thank Dr. Jeff Dawson, a member of my graduate committee and a long time mentor. Dr. Dawson was a tremendous help in setting up and troubleshooting the recording equipment.

I shared my workspace with amazing students that also deserve to be thanked. Laura McMillan, Amanda Lindeman, and Christian Nathan have all encouraged me throughout the way and have definitely made my time in the Yack laboratory much more enjoyable. Finally, I would also like to thank Edward Bruggink for allowing me to use his greenhouse nursery and for supporting the care for the butterflies.

Funding for this work was provided to Dr. Jayne Yack by the Natural Sciences and Engineering Research Council (NSERC), the Canadian Foundation for Innovation (CFI), the Ontario Innovation Trust, and the Early Researcher Award (ERA). Funding to Andrew Mikhail was provided by Carleton University and NSERC PGSM. 


\section{Table of Contents}

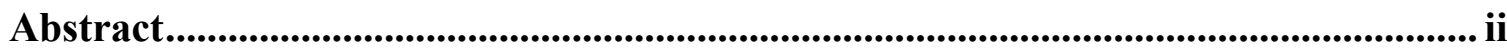

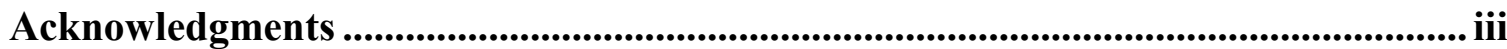

Table of Contents .......................................................................................................... iv

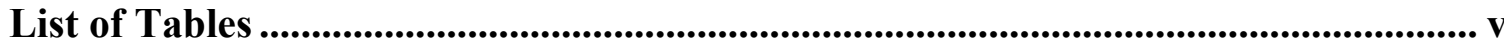

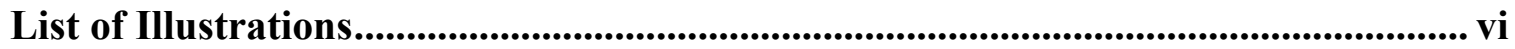

List of Abbreviations .............................................................................................. vii

Section 1: General introduction: Hearing in butterflies ............................................... 1

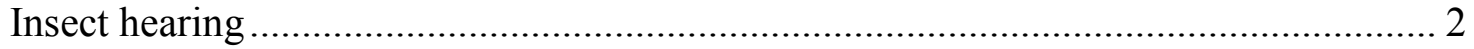

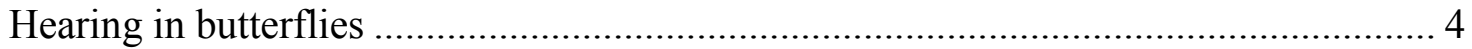

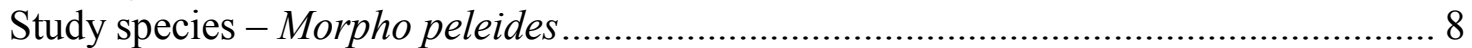

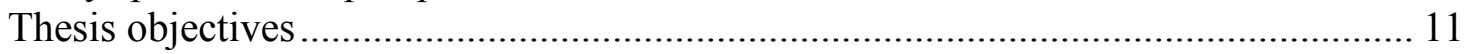

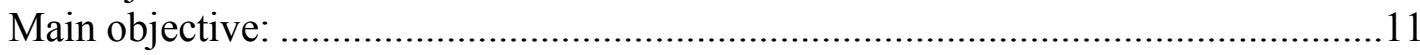

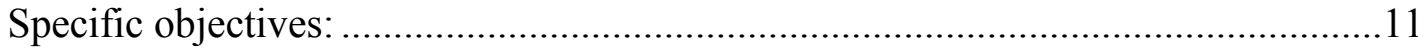

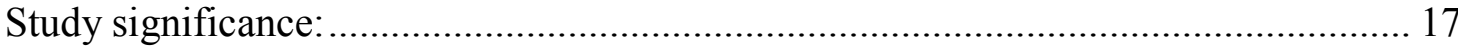

Section 2: Analysis of the neural auditory responses of the tropical butterfly Morpho

peleides (Nymphalidae) and a test of the avian hypothesis ......................................... 18

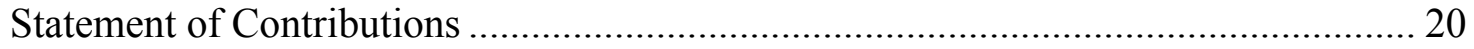

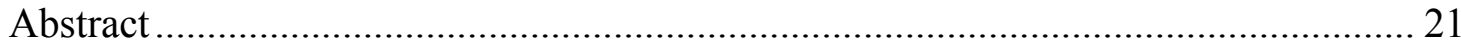

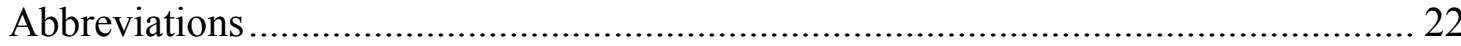

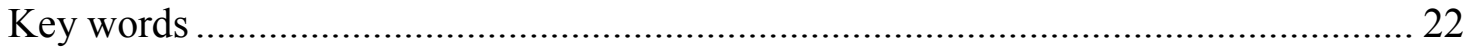

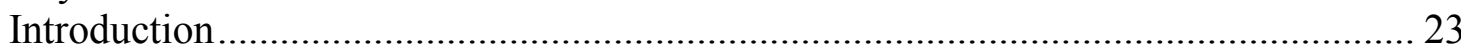

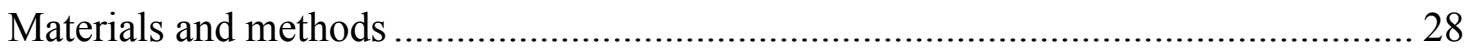

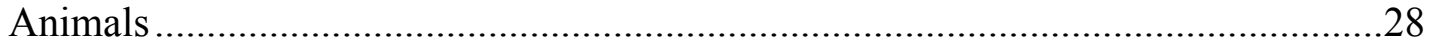

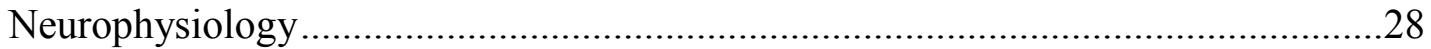

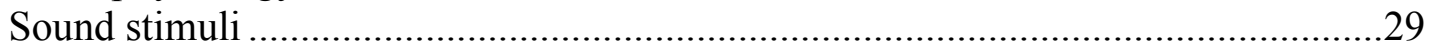

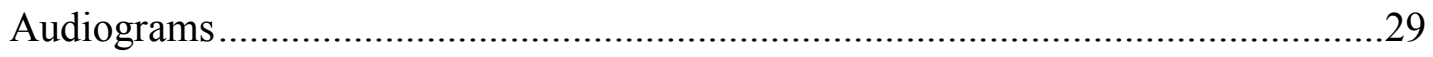

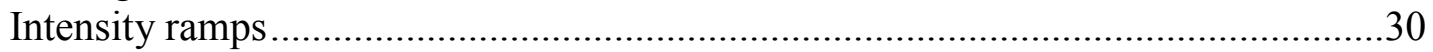

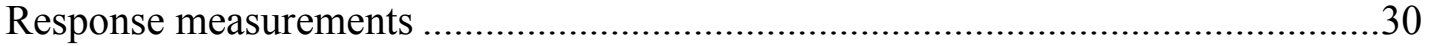

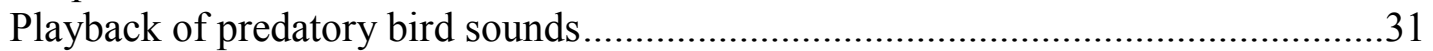

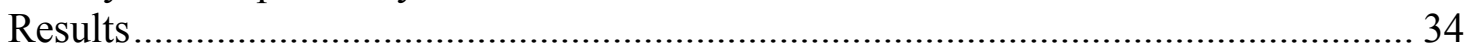

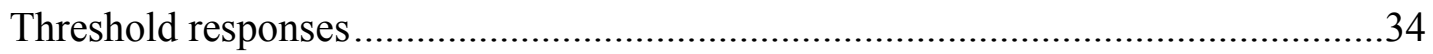

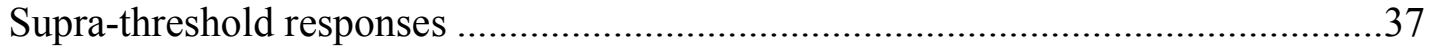

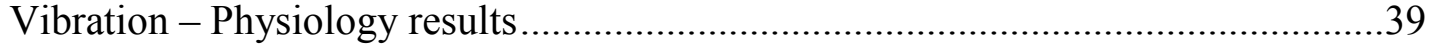

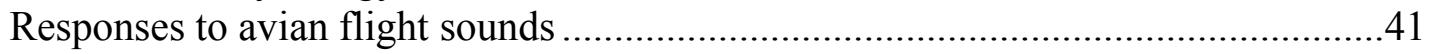

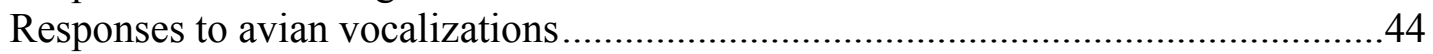

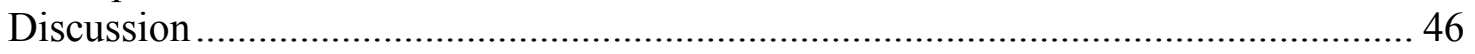

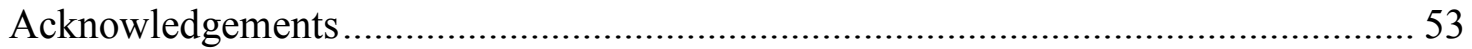

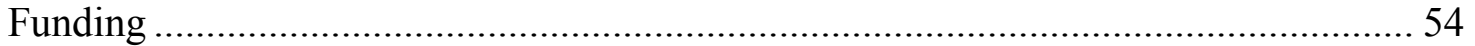

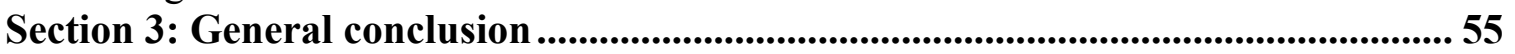

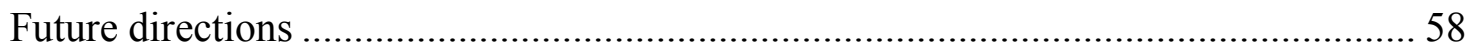

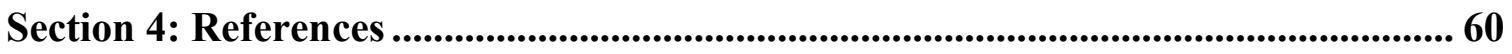

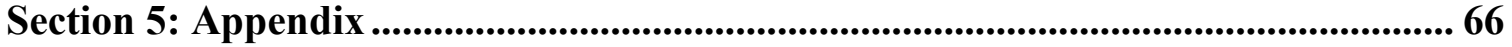




\section{List of Tables}

Table 2.1 Statistical comparisons (Mann-Whitney U-tests) of the audiograms from the two nerve branches NII and NIII in Morpho peleides.........................36 


\section{List of Illustrations}

Fig 2.1 Location and morphology of the Vogel's Organ (VO) on the butterfly Morpho

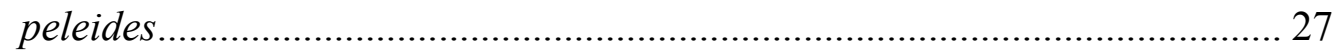

Fig 2.2 Typical compound action potential (CAP) …………………...................... 33

Fig 2.3 Auditory tuning curves for Morpho peleides....................................................35

Fig 2.4 Extracellular responses from NII and NIII in Morpho peleides...................... 38

Fig 2.5 Vibrational characteristics of the tympanal membrane and neuro-physiological

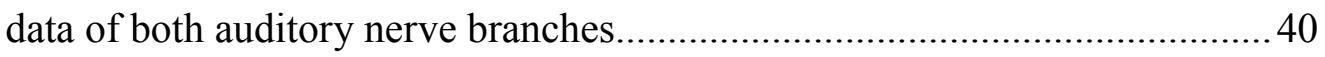

Fig 2.6 Auditory nerve responses of NII to blue jay bird flight sounds.......................42

Fig 2.7 Auditory nerve responses of NIII to blue jay bird flight sounds.................... 43

Fig 2.8 Auditory nerve responses of NIII to jacamar vocalizations.............................45

Fig 5.1 Neural response of an underwing moth (Noctuoidea) to various amplitudes of the broadband flight sounds of an eastern phoebe (Sayornis phoebe)................................66 


\section{List of Abbreviations}

LV: Laser Vibrometry

VO: Vogel's Organ

CAP: Compound Action Potential

IIN1c: Wing nerve off the pterothoracic ganglion

NTeg: Non auditory nerve branch innervating the tegula

NI: Non-auditory nerve branch to subcostal vein

NII: Auditory nerve branch to COII

NIII: Auditory nerve branch to COIIIa and COIIIb

COII: Chordotonal organ II

COIII: Chordotonal organ III

IM: Inner membrane (Tholus)

OM: Outer membrane

SC: Subcostal vein

Cu: Cubital vein

A: Anal vein 
Section 1: General introduction: Hearing in butterflies 


\section{Insect hearing}

Insects have a variety of acoustic senses that play an important role in their interaction with the environment. Acoustic communication, whether through substrate borne vibrations or air borne sounds, can allow insects to detect hosts, prey, and predators, as well as to facilitate social interactions between conspecifics (Yack, 2004; Yack and Dawson, 2007; Yager, 1999). To achieve all these functions, insect auditory systems exhibit remarkable variation in morphology (Yack, 2004; Yack and Fullard, 1993; Yager, 1999). Insects possess four acoustic receptor types; trichoid sensilla, subgenual organs, Johnston's organs, and tympanal organs, to enable detection of solid borne vibrations as well as near-field and far-field sounds (Yack and Dawson, 2008). Here, I will only discuss tympanal ears which detect the pressure component of sounds and allow detection of acoustic signals over long distances (Yager, 1999). While vertebrate ears are limited to cranial positions, insect acoustic receptors can be found on antennae (fruit flies), mouthparts (some moths), legs (crickets and katydids), wings (butterflies and lacewings), or in various positions on the thorax or the abdomen (locusts) (Yack and Dawson, 2007; Yack and Fullard, 1993). Some acoustic receptors such as the near field receptors of mosquitos, and tympanal ears of noctuid moths, locusts, and crickets, have been extensively studied, but one group of insects with tympanal ears, the butterflies, has received little attention.

Butterfly tympanal ears are found at the base of the forewings and they are of special interest because unlike many other insect tympanal ears, butterfly ears are poorly understood in terms of morphology, physiology, and function. Although butterfly 
tympanal ears were first documented in the literature over 100 years ago (Vogel, 1912), we still know very little about what butterflies hear and we do not know the function of hearing in many species. The presence or absence of tympanal ears is highly variable in butterflies (Hall, 2014), even in species that are closely related or in butterflies with overlapping geographical ranges. Additionally, within those species that have ears, there is wide variation in morphology (Hall, 2014); some butterflies are atympanate and believed to be deaf, some have simple areas of stretched cuticle that are presumed to function in audition, yet others possess remarkably complex ears with heterogeneous tympanal membranes and multiple chordotonal organs. This diversity of hearing organs in butterflies is puzzling considering that most of the eared butterflies do not produce sounds. Studying the hearing organs in butterflies not only provides insights into the function of hearing in butterflies, but also sheds light on possible secondary functions of hearing in insects such as locusts, that may be using their hearing to detect sounds from predators. Finally, understanding butterfly behaviour and sensory ecology is important to the fields of behavioural ecology and conservation biology, yet remarkably little is understood about an important sensory organ and how they use this to interact with their environment.

The series of experiments described in this thesis aim to further explore how a certain model species, Morpho peleides, encodes sound frequencies and amplitudes and how it responds to natural sounds such as those of approaching avian predators, with the ultimate goal of understanding the function of hearing in butterflies. 


\section{Hearing in butterflies}

Hearing in the order Lepidoptera is widespread and tympanal ears have been reported in at least 6 superfamilies in both moths and butterflies (Yack and Dawson, 2007). The 46 superfamilies of the order Lepidoptera are divided into moths (43 superfamilies) and butterflies (3 superfamilies) (Kristensen and Skalski, 1998; Wahlberg et al., 2005). Most moths are nocturnal and experience a strong predation pressure from echolocating, insectivorous bats. This favoured the evolution of ultrasound sensitive tympanal organs as well as associated evasive behavioural manoeuvres. Moth ears have evolved independently 6 times over the past 60 million years (Minet and Surlykke, 2003). Hearing in moths has been extensively studied (Fullard and Yack, 1993; Minet and Surlykke, 2003) in the past few decades, perhaps owing to the simple morphology and anatomy of a moth ear and its strong, consistent response to ultrasound. Most neurophysiological studies on lepidopteran hearing have been conducted on tympanal ears in moths. In comparison, hearing in butterflies has received much less attention. The three butterfly superfamilies include the Papilionoidea (true butterflies), the Hesperioidea (skipper butterflies), and the Hedyloidea (nocturnal butterflies) (Kristensen, 2003; Kristensen and Skalski, 1998). It is important to note that this classification is currently under review with more recent research (Heikkilä et al., 2012) suggesting that Hesperioidea and Hedyloidea should be classified as sister families under the Papilionoidea superfamily. In this thesis, I will be following the traditional nomenclature and taxonomic affiliations of Kristensen since it is abundantly used in the published literature (Kristensen, 2003). 
Hearing in Hedyloidea (nocturnal butterflies) is in many ways similar to hearing in moths since both groups are under similar predation pressure from bats. In fact, Hedyloidea are proposed to have evolved from moths (Wahlberg et al., 2005) and are considered by many to represent the evolutionary link between nocturnal moths and diurnal butterflies (Yack and Fullard, 2000). Hearing organs in Hedyloidea are located at the base of the forewing and have homologous chordotonal organs to Vogel's organ (VO) (Yack et al., 2007). Electrophysiological studies have shown that the ears of Hedyloidea butterflies are broadly tuned to sounds of frequencies between 40 and $80 \mathrm{kHz}$ with best hearing thresholds at $60 \mathrm{~dB}$ SPL (Yack et al., 2007). These butterflies do not show behavioural responses to low frequency sounds $(<10 \mathrm{kHz})$, but exhibit evasive manoeuvres when subjected to high frequency sounds during free flight (Yack and Fullard, 2000; Yack et al., 2007). Currently, there is no evidence of hearing in the Hesperioidea.

Studies on hearing in Papilionoidea have focused on the family Nymphalidae where the tympanal organs are at the base of the wing veins (Minet and Surlykke, 2003). In fact, to date, tympanal ears have not been described for any other family in the Papilionoidea. Nymphalidae is the largest family of butterflies with approximately 6000 described species, distributed throughout the world (Minet and Surlykke, 2003). Members of the Nymphalidae that have been described to possess hearing organs based on morphological, neurophysiological, or behavioural evidence include Heliconius $s p$. (Heliconinae) (Swihart, 1967), Erebia sp. (Satyrinae) (Ribaric and Gogala, 1996), Hamadryas sp. (Biblidinae) (Yack et al., 2000), Manataria sp. (Satyrinae) (Rydell et al., 
2003), Parage sp. (Satyrinae) (Mahony, 2006), Caligo sp. (Satyrinae) (Lucas, 2008) and Morpho sp. (Morphinae) (Lane et al., 2008; Lucas et al., 2009). With the exception of Manataria sp., all these butterflies are insensitive to ultrasound but they do respond to low frequency sounds (1-2 kHz) (Rydell et al., 2003). Manataria maculata is a crepuscular butterfly whose activity temporally overlaps with predatory insectivorous bats. Tests with an electronic dog whistle showed that M. maculata exhibited evasive flight manoeuvres when subjected to ultrasound frequencies and its threshold is estimated to be around $70 \mathrm{~dB}$ SPL (Rydell et al., 2003). The putative function of hearing in $M$. maculata is ascribed to bat detection. The remaining species respond to lower frequency sounds. The blue cracker butterfly, Hamadryas feronia, is one of the few butterfly species that produce sounds (audible clicks) with dominant frequencies between 13 and $15 \mathrm{kHz}$ (Yack et al., 2000). Males of this species produce the sounds when encountering predators, but also during territorial displays (Monge-Najera et al., 1998) and hence it is proposed that the sounds and hearing function in conspecific communication. Surprisingly, unlike many insect species with acoustic communication systems, there is a mismatch between the frequencies of the produced sounds and the frequencies of best hearing (Yack et al., 2000). Through neurophysiological recordings, Yack et al. reported that $H$. feronia responded optimally to a frequency of $1.75 \mathrm{kHz}$ with best threshold at 68 dB SPL (Yack et al., 2000). This mismatch with the sounds that they produce (13-15 $\mathrm{kHz}$ ) suggests a secondary function of hearing (predator detection) which will be further discussed further in section 2 . In all other butterfly species with ears, no sound production has been reported. Evidence of hearing in Erebia sp. comes from behavioural testing where Ribaric and Gogala found that Erebia manto and Erebia euryale either twitched 
their wings or initiated escape flight when exposed to sounds of frequencies between 125 $\mathrm{Hz}$ and $16 \mathrm{kHz}$. (Ribaric and Gogala, 1996). They estimated the best threshold to be 49 dB SPL at $1 \mathrm{kHz}$, but unfortunately no physiological evidence was reported to support their claims. Hearing in Pararge aegeria was confirmed through morphological, neurophysiological, and behavioural evidence as the small wood nymph butterfly was found to respond to sound frequencies between 3 and $18 \mathrm{kHz}$ with a best threshold of 56 dB SPL at $6.5 \mathrm{kHz}$ (Mahony, 2006). Behaviourally, P. aegeria, responded to acoustic stimuli by twitching its wings or ceasing to move (Mahony, 2006). The behavioural threshold was reported to be $88 \mathrm{~dB}$ SPL at $3 \mathrm{kHz}$ (Mahony, 2006). More recently, neurophysiological studies on the hearing of two, closely related, neotropical butterflies were reported. Morpho peleides, a diurnal butterfly was reported to be sensitive to sound frequencies between 1 and $6 \mathrm{kHz}$, with a best threshold of $58 \mathrm{~dB}$ SPL (Lane et al., 2008; Lucas et al., 2009), while Caligo eurilochus, a crepuscular butterfly was found to hear best at $3 \mathrm{kHz}$ with a threshold of $74 \mathrm{~dB}$ SPL (Lucas, 2008).

In summary, hearing organs in butterflies occur in nocturnal Hedyloidea where they respond neurophysiologically and behaviourally to ultrasound and function as bat detectors, and in diurnal butterflies where they respond mostly to low frequency sounds, although the function is not known. In Nymphalidae, many species have tympanal ears, but we have limited information on physiology and function. Most butterflies do not produce sounds and are sensitive to low frequency sounds, suggesting that hearing functions in predator detection. In this thesis, I will explore the hearing and its possible functions in M. peleides. 


\section{Study species - Morpho peleides}

This project will address questions about what butterflies are capable of detecting with their complex hearing organs by focusing on the Common Morpho butterfly, Morpho peleides (Nymphalidae, Satyrinae, Morphini). Morpho peleides is a great model organism for studying hearing in butterflies for three reasons. First, as described in detail below, the VO in M. peleides, represents hearing organs of most other butterflies (Hall, 2014) in that it is innervated by more than one chordotonal organ and the membrane is morphologically complex (Lane et al., 2008). Additionally, M. peleides is mute and diurnal, representing the life history of most other eared butterflies. Second, previous studies on M. peleides have reported on both the complex morphology of the VO (Lane et al., 2008), as well as its membrane mechanics (Lucas et al., 2009). Third, M. peleides is a large butterfly that is relatively easily imported to Canada with a commercial permit, which makes neurophysiology experiments convenient throughout the year.

Morpho peleides is a large neotropical diurnal butterfly (Fig 2.1), indigenous to Central and South America. The butterfly's large, blue, wings cause it to have an irregular bouncy flight pattern which appears as flashes of blue against the bright sky. The iridescence; common in the Morpho genus, is hypothesised to have a role in escaping from avian predators and also in attracting mates (Young, 1971). Morpho peleides uses its proboscis to feed mainly on rotting fruits (Knopp and Krenn, 2003). Natural avian predators of $M$. peleides include rufous-tailed jacamars, motmots, and large flycatchers (Young, 1971). 
Similar to other butterflies, the VO in M. peleides is located at the base of the cubital vein of the forewing (Lane et al., 2008). The tympanal membrane of M. peleides (Fig 2.1) is topographically heterogeneous consisting of a dome shaped inner membrane called the tholus (Minet and Surlykke, 2003), surrounded by a flat outer membrane (Lane et al., 2008). The inner membrane is innervated by nerve branch II (NII) and chordotonal organ COII which contains 10-15 scolopidia based on counts of scolopale caps and sensory cell bodies (Lane et al., 2008). The outer membrane is innervated by nerve branch III (NIII) and chordotonal organs COIIIa and COIIIb which contain 10-12 and 1520 scolopidia respectively (Lane et al., 2008). NII and NIII are only two of the four branches of the main forewing nerve IIN1c which extends laterally from the pterothoracic ganglion (Lane et al., 2008). The other two nerve branches from IIN1c are NTeg which innervate the tegula, and NI which runs up the subcostal vein (Lane et al., 2008), neither of which innervate the ear. Laser vibrometry studies (Lucas et al., 2009) show that at sound frequencies greater than $5 \mathrm{kHz}$ both inner and outer membranes vibrate whereas at sound frequencies below $5 \mathrm{kHz}$, vibration is primarily limited to the outer membrane. This suggests a crude mechanical frequency discrimination in M. peleides which could either extend the audible range of the butterfly or enhance its ability to differentiate frequencies (Lucas et al., 2009). Throughout neurophysiological recordings from both nerve branches, I will further examine the ability of $M$. peleides to detect sounds of varying amplitudes and frequencies.

I will also conduct preliminary investigations into the adaptive significance of hearing in butterflies using M. peleides as a model. The function of hearing in $M$. 
peleides, as well as other diurnal, mute butterflies, remains unclear. While other nocturnal butterflies within the Hedyloidea respond to the ultrasound echolocation calls of bats, the diurnal nature of $M$. peleides suggests that predation pressure from bats is weak to nonexistent. The complexity of the VO in M. peleides suggests it is not a vestigial organ. There are no accounts of M. peleides producing sounds and thus it is unlikely that the VO is used in conspecific communication. Ribaric and Gogala first suggested that diurnal butterflies could be listening to songs of avian predators (Ribaric and Gogala, 1996) and Lane et al. (2008) later suggested that M. peleides could be listening to an approaching bird's flight sounds. Fournier et al. (2013) recorded the flight sounds of eastern phoebes (Sayornis phoebe) and black-capped chickadees (Poecile atricapillus), and showed that M. peleides responds physiologically to playbacks of the flight sounds of these birds as they forage. Birds are a major predator of diurnal butterflies (Sakurai, 2011) and hearing the passive cues of bird flight, or possibly active calls of an approaching bird would favour butterflies possessing such ability. Further evidence that supports this hypothesis includes the overlap of bird flight sounds with the hearing range of M. peleides (Fournier et al., 2013; Lucas, 2008; Lucas et al., 2009) and other diurnal butterflies (Mahony, 2006). Alternatively, they may be listening to other cues of the presence of birds, such as territorial calls. I will explore this further in section 2 of this thesis. 


\section{Thesis objectives}

Main objective:

The main goal of this study is to understand what the butterfly M. peleides is capable of hearing. I characterize the neurophysiological responses of the two auditory nerve branches (NII and NIII) innervating the inner and outer membrane of VO to pure tone stimuli and natural sounds. Ultimately, this will lead to better understanding of the function of ears in diurnal butterflies.

Specific objectives:

1- Is the nervous system capable of discriminating different frequencies?

To react appropriately, all hearing animals, including insects, must extract information from the sounds they hear. Frequency is one parameter of sound that can carry information relevant to the listener, and insects have evolved various methods of detecting and discriminating frequencies (Pollack and Imaizumi, 1999; Stumpner and von Helversen, 2001).

The ability to discriminate frequencies can be crucial to some species, and ecologically irrelevant to others. For example, in field crickets, frequency discrimination is important because it allows them to differentiate between the ultrasound calls of predatory bats and the lower frequency calls of mates. Research shows that crickets categorically divide sound frequencies between attractive $(<16 \mathrm{kHz})$ and repulsive sounds $(>16 \mathrm{kHz})$ (Wyttenbach et al., 1996). Additionally, the ability to finely discriminate frequencies allows crickets to identify species conspecifics and also judge the age and 
fitness level of the caller (Bertram and Rook, 2011; Wagner, 1992). In other insects such as moths, which use their hearing primarily for bat detection, frequency discrimination is not as important. From a moth's perspective, the exact frequency of the predatory bat's call is ecologically irrelevant since behaviourally, the moth's response would be identical. In fact, some moths are able to accomplish the function of bat detection and evasion with just a single neuron per ear (Surlykke, 1984). Some insects such as katydids are able to use frequency discrimination to estimate the distance to the sound source (Thiele and Bailey, 1980). This is possible because as sound travels through the environment, its spectrum changes. Higher frequencies of the sound are attenuated disproportionately more with distance, both because they are easily blocked by small objects in the environment, and because frictional loss of energy is greater for higher frequencies (Bennet-Clark, 1998).

Insects can achieve frequency discrimination in many ways. In ensiferans such as katydids and crickets, each receptor may be tuned to a particular sound frequency and there is a relationship between the position of a receptor and the frequency to which it is most sensitive (Stumpner, 1996). The tympanal membrane in crickets and katydids vibrates in a spatially uniform manner with respect to sound frequencies (Michelsen and Larsen, 1978). The mechanics of the inner ear (internal membranes and air cavities) may not respond in a spatially uniform manner to different frequencies (Kalmring and Jatho, 1994). The result is that one end of the hearing structure is more efficiently stimulated by low frequencies while the other end is more efficiently stimulated by higher frequencies. This tonotopic organization is akin to vertebrate auditory systems (von Békésy, 1990), 
where the basilar membrane spatially separates sound frequencies along its length. It is also possible that factors intrinsic to each receptor cell results in different frequency sensitivities (Oldfield, 1985).

In other insects, crude frequency analysis can be achieved mechanically at the level of the tympanal membrane. The attachment sites of chordotonal organs in grasshoppers and locusts correspond to the sites of maximum deflection in the tympanal membrane (Windmill et al., 2005). The tympanal membrane in grasshoppers is heterogeneous with different areas of the membrane having variable thicknesses (Windmill et al., 2005). Since the different frequencies of sound vibrate the tympanal membrane differently, it is possible that the location of the chordotonal organs on the membrane offer a mechanical first step of frequency discrimination (Windmill et al., 2005). The frequencies that grasshoppers are most sensitive to, correlate to the areas of maximal tympanal deflection (Windmill et al., 2005) and this acoustic filtering of certain frequencies at the peripheral level can limit the frequencies that an insect can detect. The ability to discriminate frequencies at the periphery has been reported in locusts and grasshoppers (Windmill et al., 2005), but the adaptive significance of this ability remains unclear. Research into similar, morphologically complex ears, such as those of butterflies, can offer insights into the function of hearing in these insects.

In M. peleides, the outer and inner membrane vibrate differently in response to sounds of different frequencies (Lucas, 2008; Lucas et al., 2009) and the butterfly may potentially be able to discriminate sounds of different frequencies by comparing the 
neural activity in NII and NIII. Identification of frequency may allow the butterfly to detect and identify the source of the sound, thereby differentiating possible predatory threats from other sounds in the environment. My first objective was to compare the frequency responses of both nerve branches and relate that to the vibrational properties of the membrane to determine if the M. peleides could encode differences in frequency of sound stimuli. I predicted that the frequency sensitivities of each nerve branch would follow the vibrational properties of the membrane attached to the respective chordotonal organ(s). For example, at low frequencies $(\sim 2.5 \mathrm{kHz})$ where vibrations are limited to the outer membrane, I predicted that NIII would exhibit a larger response. At higher frequencies $(\sim 6.5 \mathrm{kHz})$ where the inner membrane vibrates more than the outer membrane, I predicted a larger response from NII compared to NIII.

\section{2- Is the nervous system capable of encoding amplitude changes?}

The amplitude of a sound is another characteristic that would be of importance to the listener. Many insects are able to encode small changes in the amplitude of a sound and use this ability to estimate the distance to the sound source. Sound amplitude decreases with increasing distances according to the inverse square law for sound attenuation, which states that for every doubling of distance from the sound source, there is a $6 \mathrm{~dB}$ SPL reduction in sound level (Greenfield, 2002). Noctuid moths have two auditory cells, (A1 and A2), that differ in their sensitivities by approximately $20 \mathrm{~dB}$ (Yack and Dawson, 2007). This sensitivity difference presumably allows the moth to employ different behaviors depending on the intensity of the signal it detects. A low amplitude or less intense signal from a bat that is far away will only activate the low 
threshold A1 cell, and the moth will respond by flying away from the signal; negative phonotaxis (Roeder, 1964). A high amplitude or intense signal from a quickly approaching bat will activate the high threshold A2 cell, and the moth will respond by erratic flight patterns or dives (Roeder, 1964). Different thresholds may also potentially increase the dynamic range, allowing moths to detect a wider range of intensities (Spangler, 1988).

Although there is limited evidence to date that butterflies listen to bird flight sounds (Fournier et al., 2013) or bird calls, it is possible that butterflies possess the ability to detect differences in a signal's intensity for the same purpose as moths. It would be adaptive for the butterfly to have the ability to differentiate sounds emitted by far birds versus close birds, to be able to employ appropriate behaviors. My second objective would be to compare the sensitivities of both nerve branches and explore how they respond to sounds of different amplitudes.

3- How does each branch respond to natural sounds such as bird flight or bird calls?

The functional significance of hearing in butterflies remains unknown and to explore this, it is important to relate the physiology of hearing, to sounds that the butterfly would experience in its natural environment. The idea that insects may use their hearing to detect passive cues in the environment has not been sufficiently explored and only recently have a few studies (Fournier et al., 2013; Lane et al., 2008; Lucas et al., 2009) suggested that a sense of hearing in butterflies might function for bird detection. The third and final objective of my thesis will be to explore how the two nerve branches 
respond to natural sounds such as the broadband sounds produced passively during flight by approaching birds and the low frequency vocalizations of predatory species. 


\section{Study significance:}

Understanding the relationships between morphology and physiology can provide insights into: 1) mechanics for processing acoustic information - transduction from the tympanal membrane and 2) function of hearing in butterflies and other diurnal insects. To this day, the adaptive significance of hearing in diurnal butterflies remains a mystery. Exploring how the morphology of the butterfly's ear contributes to the physiology of hearing will ultimately lead to a better understanding of the function of audition in butterflies and other insects. As explained in section 3, the conclusions drawn from the results of this work are not limited to butterflies, but could be extended to most eared diurnal insects with similar hearing. More broadly, understanding the physiology of hearing in relation to the life history of the animal could lead to better and more focused conservation efforts. The results of the experiments outlined in this thesis will also shed light on the evolution of auditory senses in the context of avian predation which has never before been explored. 


\section{Section 2: Analysis of the neural auditory responses of the tropical butterfly Morpho peleides (Nymphalidae) and a test of the avian hypothesis}

A portion of this section has been published in a peer reviewed journal and the rest is being adapted into a manuscript for submission to a peer reviewed journal.

Fournier, J.-P., Dawson, J., Mikhail, A. and Yack, J. E. (2013). If a bird flies in the forest, does an insect hear it? Biology letters 9, 20130319.

Mikhail, A., Lewis, J., and Yack, J. (2014). What does a butterfly hear? Journal of Comparative Physiology A (In preparation) 


\title{
What does a butterfly hear? Sound frequency and amplitude detection in Morpho peleides (Nymphalidae)
}

\author{
Andrew P. Mikhail ${ }^{1}$, John E. Lewis ${ }^{2}$, and Jayne E. Yack*1 \\ ${ }^{1}$ Department of Biology, Carleton University, Ottawa, Canada \\ 1125 Colonel By Drive, Ottawa, ON, Canada. K1S 5B6 \\ ${ }^{2}$ Department of Biology, University of Ottawa, Ottawa, Ontario, Canada \\ 75 Laurier Avenue East, Ottawa, ON, Canada. K1N 6N5 \\ *Corresponding author; \\ Email: jyack@connect.carleton.ca; Tel: 613 520-3887; Fax: 613 520-3539
}

Running title: What does a butterfly hear? 


\section{Statement of Contributions}

Andrew Mikhail designed the experiments, collected the neurophysiology data, analyzed the results, and wrote the manuscript. John Lewis helped with experiment design, MATLAB data analysis, and revised the manuscript. Jayne Yack designed the experiments, helped with data collection, and revised the manuscript. The bird flight

recordings were done by Jean-Paul Fournier as a portion of his M.Sc. research in 2009. The membrane mechanics recordings were done by Katie Lucas as a portion of her M.Sc. research in 2009. 


\begin{abstract}
Many butterflies have well developed tympanal ears on their wings, yet to date, little is known about how these ears respond to sound or what butterflies are capable of hearing in their natural environments. The tympanal ear of many butterflies, including the tropical butterfly Morpho peleides, comprises an outer membrane with an inner dome which are innervated by two separate auditory nerve branches (NII and NIII) and their respective sensory organs. We employed extracellular neurophysiological recordings to measure the threshold response of each nerve branch to sounds of varying frequency and amplitude. We found that both nerve branches are similarly tuned, with NIII being more sensitive than NII at the best hearing frequency. The responses to suprathreshold stimuli were frequency-sensitive, with NIII responding best from 1-3 kHz and NII responding best from 4-6 kHz. To investigate the adaptive significance of hearing in butterflies, we tested how the auditory system responded to both passive and active sounds produced by one of their major predators, birds. Cells in NII and NIII responded in a bursting pattern to playbacks of the broadband cyclic sounds produced passively during flight of blue jays (Cyanocitta cristata). Additionally, this is the first study to demonstrate that the butterflies can also detect the vocalizations of birds, as $M$. peleides was able to detect the low frequency calls of one of its main avian predators, the rufous-tailed jacamar (Galbula ruficauda), providing further evidence that butterflies, and possibly other diurnal insects, could be using their sense of hearing to detect and avoid avian predation.
\end{abstract}




\begin{abstract}
VO-Vogel's organ
CAP-Compound Action Potential
\end{abstract}

Abbreviations

Key words

\title{
Butterfly
}

Ear

Morpho peleides

Bird

Predator detection

Neurophysiology

Hearing

Tympanal

Auditory 


\section{Introduction}

Audition constitutes an important part of the sensory ecology and survival of many insects which use sounds to identify and locate mates, establish territories, detect and evade predators, and localize hosts (Yack, 2004; Yack and Dawson, 2007; Yager, 1999). Given the wide diversity of sounds that different insects need to listen to, they have evolved a remarkable diversity of sound detectors that are capable of detecting a wide range of frequencies and amplitudes. Insects have to extract information from the sounds they hear in order to react appropriately and as a result, hearing systems in insects have evolved to discriminate frequencies, detect amplitude differences and localize sound sources, often with remarkable sensitivity and precision (Hoy and Robert, 1996; Robert and Göpfert, 2002; Stumpner and von Helversen, 2001). Many insect ears have been studied extensively, and have consequently provided insights into novel and diverse mechanisms that small insects have evolved to overcome challenges associated with sound detection. While hearing has been studied extensively in insects such as moths, cicadas, locusts, and crickets, one popular insect group -the butterflies- has not been studied in detail for their hearing. In this study we report on the unusual hearing organ of the butterfly Morpho peleides, propose how it has come up with a novel way of processing sounds, and provide evidence that butterflies may use their hearing to detect the passive sound cues produced by predators; something that has been well known for the vertebrate hearing system, but almost completely overlooked as a function of hearing in insects. 
Many species of butterflies belonging to the large family, Nymphalidae, which includes widely studied species such as monarchs, morphos, and lacewings, have well developed ears at the base of their wings (Hall, 2014; Lane et al., 2008; Ribaric and Gogala, 1996; Rydell et al., 2003). Despite extensive research of these butterflies with respect to their sensory ecology, migration patterns, and visual and chemical senses, almost nothing is known about why they have ears, and what they are capable of hearing. Moreover, they have unique tympanal morphology, with a complex membrane that is innervated at different regions by separate sensory organs (Lane et al., 2008; Vogel, 1912). Research on this group will not only provide key insights into the functional properties of a novel ear, but will provide insights into how butterflies interact with their environments.

Butterfly tympanal ears were first described in Nymphalidae butterflies in 1912 and named Vogel's organs (VO) after their discoverer (Vogel, 1912). Located at the base of the ventral forewing, butterfly VOs vary in size and shape, but like other insect tympanal ears (Yager, 1999), they are comprised of a tympanal membrane, innervated by chordotonal organs, and backed by tracheal air-sacs. At the time, Vogel had no direct evidence that the VOs could detect sound, but since then, a handful of studies on different species have provided evidence using behavioural (Ribaric and Gogala, 1996; Rydell et al., 2003) and neurophysiological (Lane et al., 2008; Yack and Fullard, 2000) tests that VOs indeed respond to sound. At present, most of what we know about hearing in Nymphalidae butterflies comes from a handful of studies on a few different species (Lane et al., 2008; Lucas et al., 2009; Ribaric and Gogala, 1996; Rydell et al., 2003; Swihart, 
1967; Yack et al., 2000), but one species in particular, Morpho peleides, represents a good model for understanding what most butterflies hear. Morpho peleides, like most other Nymphalidae butterflies is diurnal and mute and has a well-developed ear that externally looks like most other butterfly ears. Being relatively large and readily available, M. peleides with its morphologically complex VO, represents an exciting opportunity to explore the function of hearing outside the context of conspecific communication and bat detection.

Morpho peleides' VO is composed of a topographically heterogeneous tympanal membrane, consisting of a dome shaped inner membrane (tholus) surrounded by a flat outer membrane (Fig 2.1). The inner membrane is innervated by chordotonal organ COII and nerve branch II (NII), while the outer membrane is innervated by chordotonal organs COIIIa and COIIIb which connect to nerve branch III (NIII) (Lane et al., 2008). Examination of the tympanal membrane using laser vibrometry revealed two distinct modes of vibration depending on the incident sound frequency, yet preliminary physiological tests show that both NII and NIII are similarly tuned (Lucas et al., 2009). Other insects with heterogeneous tympanal membranes such as locusts, utilize the complex structure of the membrane to produce a travelling wave that decomposes incoming sound stimuli into low and high frequency components (Michelsen, 1971; Windmill et al., 2005). The locations of the underlying clusters of sensory cells correspond to the areas of maximal membrane displacement, allowing for mechanical frequency partitioning at the membrane level (Windmill et al., 2005). 
Currently, the functional significance of the chordotonal organs of M. peleides is unknown. In insects, multiple chordotonal organs may be used for frequency partitioning (Windmill et al., 2005) or for expanding the dynamic range (Mason and Faure, 2004), but these theories have not been tested in butterflies. Morpho peleides, being diurnal and mute means it is unlikely that its ears are used for bat detection or conspecific communication, however, recent evidence suggests that the ear might function in avian predator detection (Fournier et al., 2013). Understanding the function of hearing in $M$. peleides, can offer insights into the adaptive significance of hearing in other diurnal butterflies as well as other eared insects such as locusts. In this study we further explore the hearing capability in M. peleides by measuring and comparing the responses of each nerve branch to sounds of varying frequency and amplitude, as well as to sounds of avian predators. The purpose of this study is to understand what sounds the Morpho butterfly can detect with its two nerve branches and multiple chordotonal organs. We have two specific objectives: (1) to examine the physiological response of both auditory nerve branches with respect to stimulus frequency and amplitude to gain an understanding of what M. peleides is capable of hearing and how the two nerve branches and their respective chordotonal organs contribute differently to hearing. (2) to examine how the auditory nerve branches respond to natural sounds in the environment, such as bird flight and bird songs and based on our observations, to pose hypotheses on the function of hearing in diurnal butterflies. 

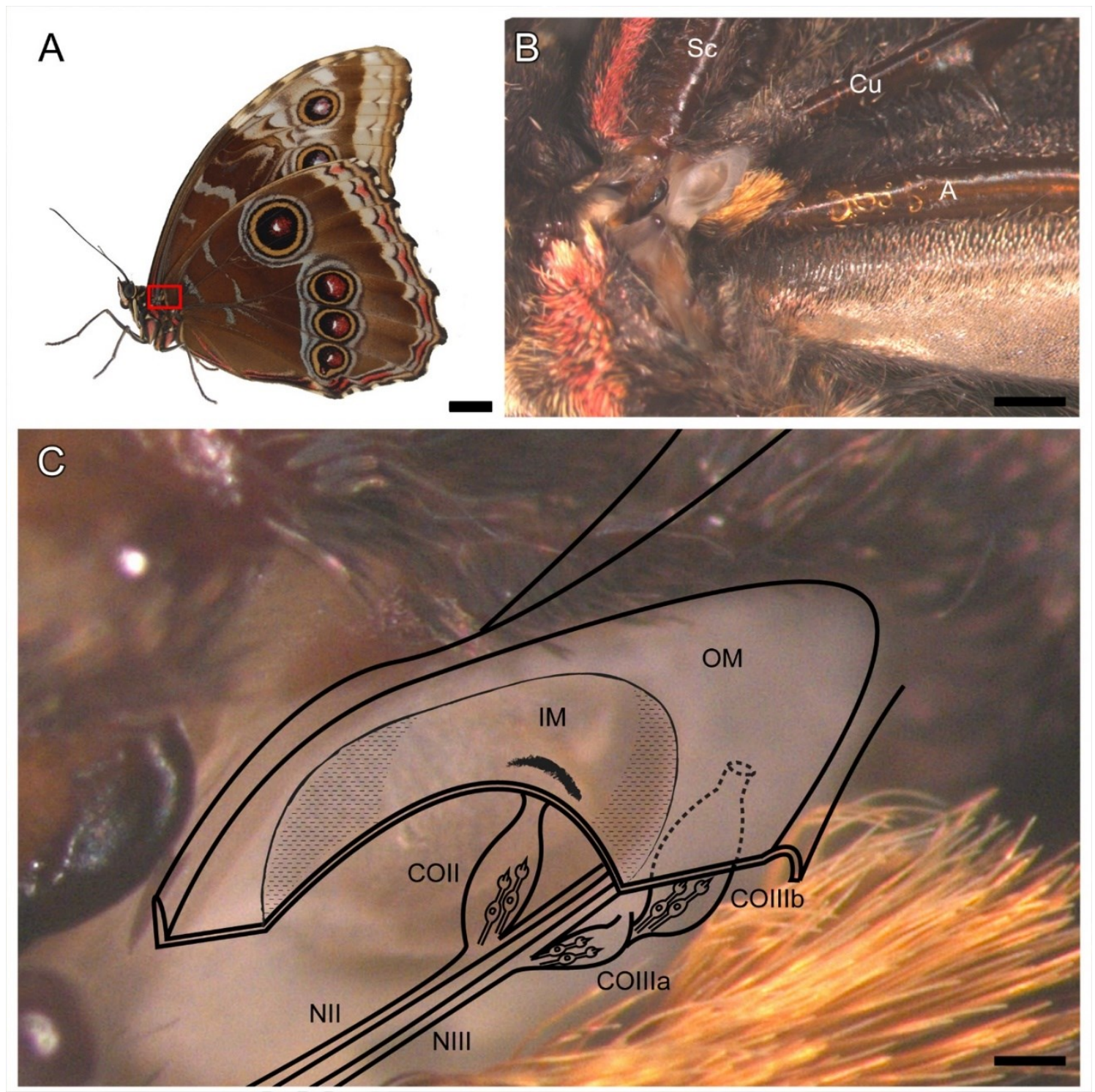

Figure 2.1: Location and morphology of the Vogel's Organ (VO) on the butterfly Morpho peleides. (A) Natural resting position of $M$. peleides, with the VO exposed on the forewing (location indicated by the red rectangle). (B) Close-up of $\mathrm{VO}$ on left wing with the subcostal ( $\mathrm{Sc}$ ), cubital (Cu), and anal (A) veins visible. (C) Light micrograph of $\mathrm{VO}$ superimposed on drawing of the nerve branches. The inner membrane (IM), also called the tholus, is innervated by nerve branch II (NII) and chordotonal organ COII, whereas the outer membrane (OM) is innervated by nerve branch III (NIII) and chordotonal organs COIIIa and COIIIb. Scale bars $=1 \mathrm{~cm}$ in $A ; 1 \mathrm{~mm}$ in $B ; 100 \mu \mathrm{m}$ in C. 


\section{Materials and methods}

\section{Animals}

Morpho peleides were obtained as pupae from London Pupae Sales (Oxfordshire, UK: Permit number: P-2011-04393). The chrysalides were housed in mesh cages in a greenhouse at Carleton University, Ottawa, where they were exposed to natural light conditions and temperature fluctuations between $25^{\circ} \mathrm{C}$ and $40^{\circ} \mathrm{C}$. Humidity in the cage fluctuated between 55-75\%. Upon eclosion, the butterflies were provided with orange slices ad libitum and used for experiments 1-6 days following emergence.

\section{Neurophysiology}

Standard physiology techniques (Lane et al., 2008) were performed to expose the main wing nerve, IINIc, and its three branches; NI, NII, NIII of which the latter two innervate the VO. Electrolytically sharpened stainless steel hook electrodes were used in a single-ended configuration (with the ground electrode in the abdomen) to record auditory evoked potentials. Once a stable signal was obtained from one nerve branch, the other branches were severed to ensure the neural activity recorded originated only from the nerve branch under study and to minimize any potential interference. Neural signals were amplified by a GRASS P-55 preamplifier (West Warwick, RI, USA) and displayed on a Tectronix (TDS2002C) (Beaverton, ON, Canada) digital oscilloscope. The signal was also fed through an audio monitor to listen for auditory responses. Both the sound stimuli and neural responses were recorded as .wav files at a sampling rate of $88.2 \mathrm{kHz}$ using a Fostex FR-2: Field Memory Recorder (Akishima, Tokyo, Japan) for offline 
analysis. All recordings were performed within a Faraday cage lined with acoustic foam $(1.2 \mathrm{~m} \times 0.9 \mathrm{~m} \times 0.8 \mathrm{~m})$.

\section{Sound stimuli}

Acoustic stimuli were presented to the butterfly as $30 \mathrm{~ms}$ trapezoidal pulses (including 5ms on/off linear ramps), generated by an RX6 multifunction digital signal processor by Tucker Davis Technologies (TDT) (Alachua, FL, USA), and shaped by the associated TDT software on a PC. Frequencies between 0.5 and $3 \mathrm{kHz}$ were amplified by a TDT SA1 stereo amplifier and broadcast from a generic woofer at $80 \mathrm{~cm}$ from the specimen, whereas frequencies between 4 and $25 \mathrm{kHz}$ were attenuated by a TDT PA5 programmable attenuator and broadcast from a CTS tweeter (KSN1167A) at 30cm from

the specimen. Both the woofer and tweeter were calibrated by calculating the sound level in $\mathrm{dB}$ SPL at the specimen using continuous sine waves measured by a Brüel \& Kjær Type 2239 sound level meter and a Brüel \& Kjær Type 4135 microphone with its associated Type 2610 measuring amplifier.

\section{Audiograms}

Hearing thresholds for both nerve branches NII and NIII were determined online by listening for neural spikes that occurred consistently in tandem with a sound pulse. An oscilloscope displaying the neural signal was also monitored in real time to confirm the responses. Threshold was determined, at $1 \mathrm{kHz}$ intervals from 0.5 to $25 \mathrm{kHz}$, as the lowest sound pressure level that consistently elicited a response ( $\geq 90 \%$ of the time). This method of determining thresholds has been commonly used to construct audiograms in butterflies (Lane et al., 2008; Lucas et al., 2009) as well as other insects (Fournier et al., 
2013; Fullard et al., 2010; Nakano et al., 2008). The list of test frequencies was presented to the butterfly in random sequence, and at the end of the audiogram, the first three test frequencies were presented to the butterfly once again and the thresholds re-determined. The audiogram was only included in the results if these thresholds were within $\pm 3 \mathrm{~dB}$ of the original thresholds; this ensures that any variation in threshold was not due to habituation effects or other changes in the animal's condition. Once completed, the audiograms from both nerve branches were compared and any differences in tuning and sensitivity were analyzed.

\section{Intensity ramps}

In order to assess the butterfly's response to sounds of varying amplitudes, we broadcast a series of pulses, while gradually increasing the intensity and recording the responses. These intensity ramps, consisted of $30 \mathrm{~ms}$ pure tone trapezoidal pulses that were broadcast at $1 \mathrm{~s}$ intervals. The sound amplitude increased, every 10 pulses, in $2 \mathrm{~dB}$ increments from 60 to $85 \mathrm{~dB}$ SPL and we recorded the responses to sound frequencies between 1 and $8 \mathrm{kHz}$ as described above.

\section{Response measurements}

After collecting the response data from the intensity ramps, we analyzed the compound action potential (CAP) resulting from each pulse using custom MATLAB scripts. Each identical set of 10 pulses were averaged (Fig 2.2) and for each averaged trace, we examined the neural activity $100 \mathrm{~ms}$ before stimulus onset to determine the background level (4 X SD) and then compared it to $100 \mathrm{~ms}$ following stimulus onset to measure the neural response. The strength of the response was quantified in two ways: 
(1) the first spike of the CAP, after stimulus onset that was at least over 4 times the background activity; (2) the total area between the neural trace and background level over the $100 \mathrm{~ms}$ interval. Since amplitude alone does not provide information about the length of the response, the area of the response was also used to incorporate both the amplitude and duration of the CAP (Fig 2.2). Averaged intensity-frequency plots from NII and NIII (Fig 2.5) were constructed based on frequency scans for 1, 2, 3, 4, 6, and $8 \mathrm{kHz}$ and the response was colour coded, interpolated, and smoothed in MATLAB.

\section{Playback of predatory bird sounds}

In order to assess the neural response to natural sounds, we played back recordings of bird flight and bird vocalizations to butterfly preparations, and recorded the response from both nerve branches. Flight sounds of blue jays (Cyanocitta cristata) were previously recorded at the Queen's University Biological Station $\left(44^{\circ} 34 \mathrm{~N} 76^{\circ} 19 \mathrm{~W}\right)$ in the summers of 2009 and 2010 at a sampling rate of $192 \mathrm{kHz}$ using an Earthworks QTC40 microphone (4 Hz - $40 \mathrm{kHz} \pm 1 \mathrm{~dB}$, Milford, NH, USA). Blue jays were found locally and were lured in with a bird feeder and tethered insects allowing for multiple recordings. Among the bird flight sounds recorded (eastern phoebe (Sayornis phoebe), black-capped chickadee (Poecile atricapillus), and blue jays (Cyanocitta cristata)), there were some differences in the foraging strategies and wing beat frequencies (Fournier, 2011; Fournier et al., 2013), however, the flight sounds of blue jays are representative of other birds in that they are broadband and pulsed with peak frequencies around $1 \mathrm{kHz}$ (Fournier, 2011; Fournier et al., 2013). Four different intensities of these sounds representing approximately $30 \mathrm{~dB}$, were played back to butterfly preparations, $30 \mathrm{~cm}$ away, using an Avisoft ScanSpeak speaker (1-120 kHz) and Avisoft USG Player 116. 
The neural responses from both nerve branches to these blue jay flight sounds were examined to determine if the butterflies were able to neurally encode the increasing loudness of an approaching bird's acoustic signature.

Recordings of jacamar vocalizations were obtained from xeno-canto (www.xenocanto.org), a collection of over 150,000 bird recordings, some of which were recently used in scientific papers (Brumm and Naguib, 2009; Weir and Wheatcroft, 2011). The jacamar vocalizations, consisting of a series of notes gaining in speed and ending in a trill, function in mate selection and territoriality (Hilty, 2003). Jacamars call throughout the day from the first light of dawn and into the evening (Hilty, 2003), temporally overlapping with the activity of many butterflies including $M$. peleides. The jacamar vocalizations were played back to butterfly preparations at three different intensities, representing approximately $25 \mathrm{~dB}$, and the resulting responses were analyzed to determine if the butterflies were able to neurally encode the varying loudness of these predatory bird calls. 


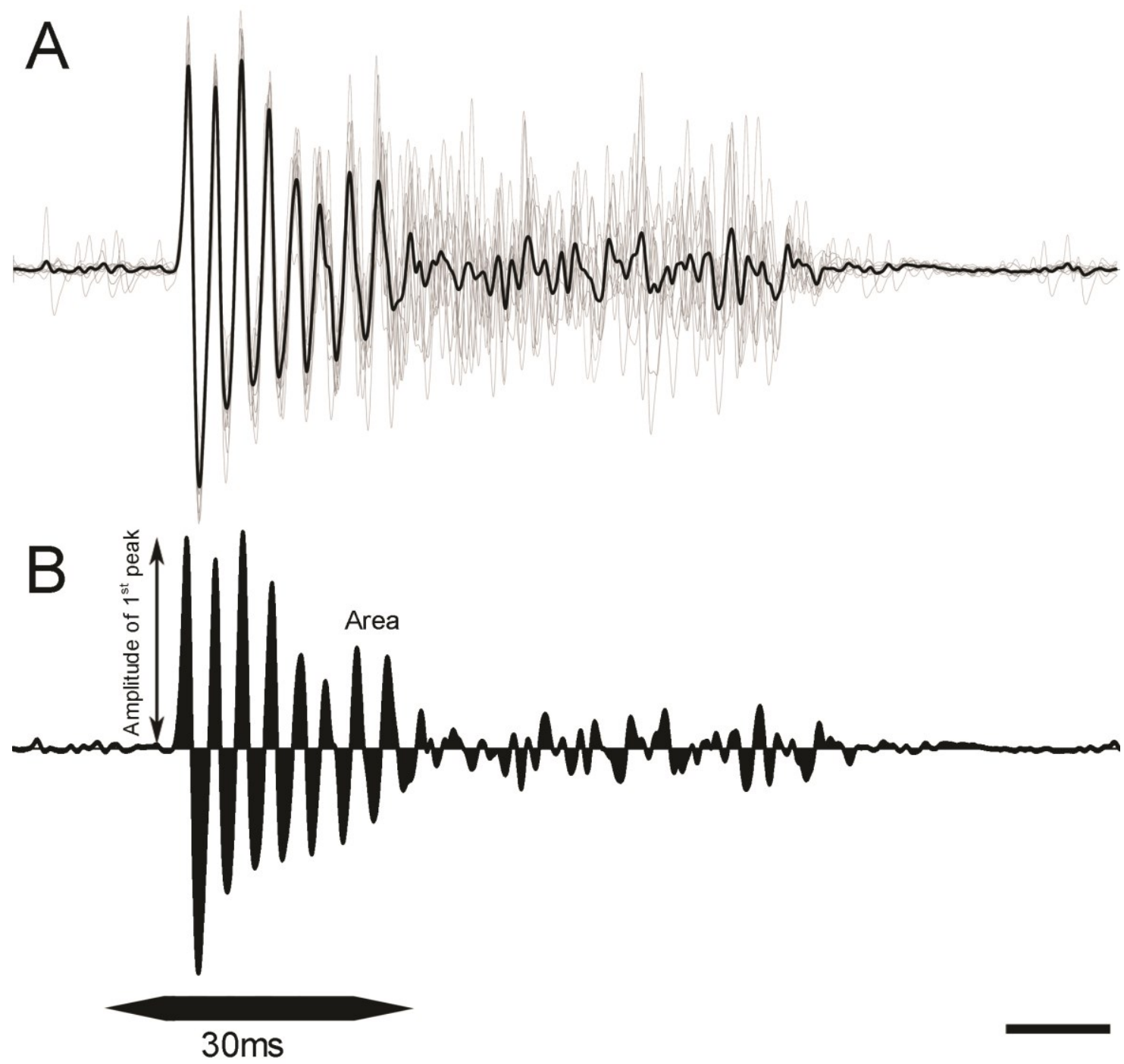

Figure 2.2: Typical compound action potential (CAP) from NIII in response to a $30 \mathrm{~ms}, 2 \mathrm{kHz}$ stimulus played at $80 \mathrm{~dB}$ SPL: (A) 10 individual CAPs (grey) and the averaged CAP (black). (B) Measurements from the averaged CAP; the amplitude of the first peak and area (shaded) were measured. Scale bar $=10 \mathrm{~ms}$. 


\section{Results}

\section{Threshold responses}

The frequency response of the ear of $M$. peleides was tested by performing extracellular nerve recordings from each of NII and NIII on a total of 12 ears from 10 individuals (Fig 2.3). Both branches responded to sound frequencies (30ms pure tone pulses) between 1 and $20 \mathrm{kHz}$; this is consistent with previous studies on the same species (Lane et al., 2008; Lucas et al., 2009). The audiograms from NII and NIII were statistically compared (Table 2.1) for differences in threshold sensitivity and tuning. Both nerve branches were most sensitive at the same frequencies (between 2 and $3 \mathrm{kHz}$ ) as we found no significant differences between the frequency at the lowest threshold for NII and NIII (Mann-Whitney U-test, $\mathrm{p}=0.8103$ ). To examine any differences in the sharpness of the tuning, we measured the bandwidth at $10 \mathrm{~dB}$ above threshold for each animal and once again, found no significant differences between NII and NIII (Mann-Whitney Utest, $\mathrm{p}=0.2627$ ) (Table 2.1). Despite the similar tuning, NIII was more sensitive than NII, having a lower threshold at the best frequency (Mann-Whitney U-test, $\mathrm{p}=0.0455$ ). The increased sensitivity of NIII was also indicated by an increased total audiogram area under 70, 80, and $100 \mathrm{~dB}$ SPL for each animal (Mann-Whitney U-test, $\mathrm{p}=0.0203$, $\mathrm{p}=0.0308$, and $\mathrm{p}=0.0455$ respectively) (Table 2.1 ). In summary, our audiogram results show that both nerve branches do not differ in frequency tuning or best frequency, but NIII is a few decibels more sensitive than NII at the best frequency. 

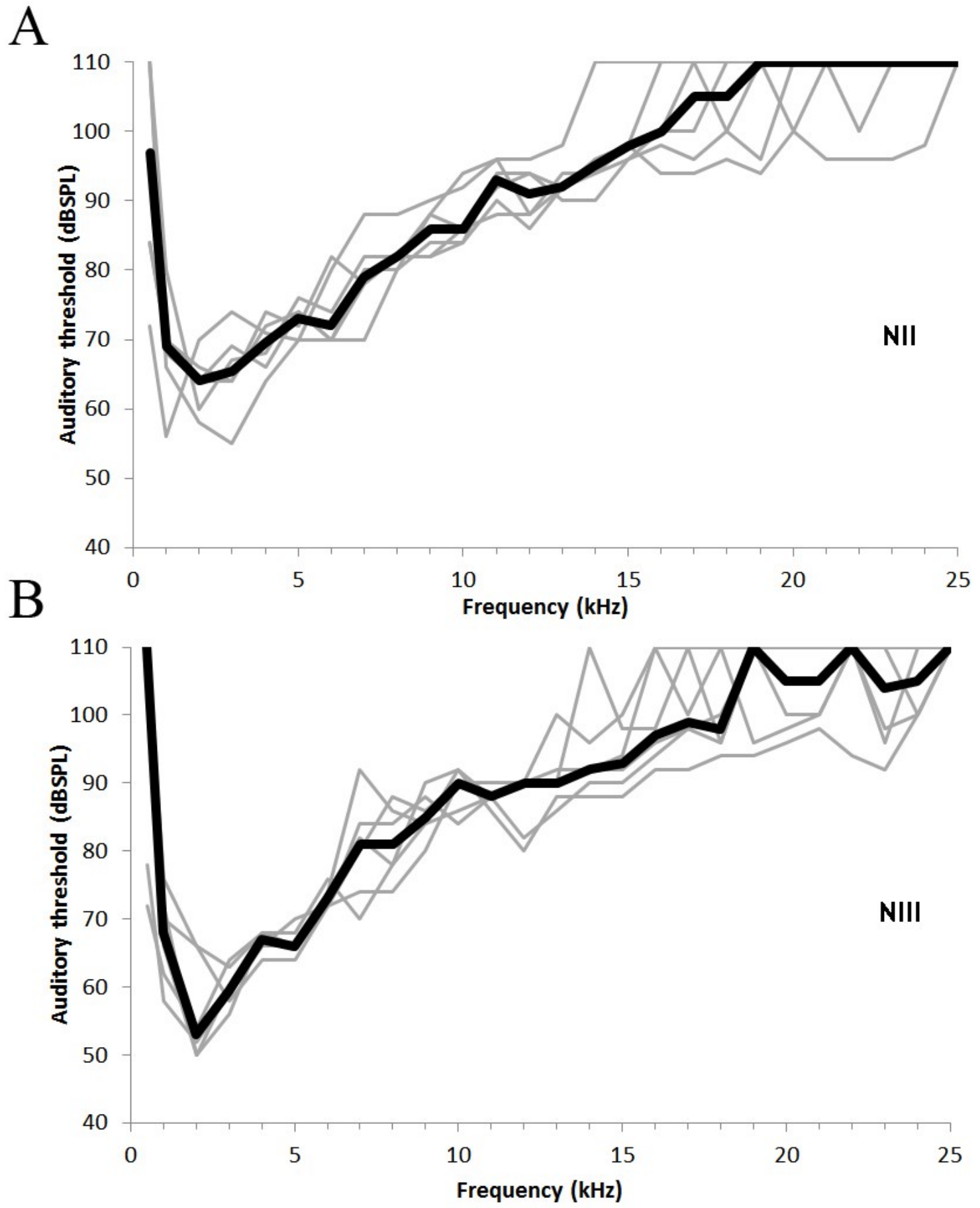

Figure 2.3: Auditory tuning curves for Morpho peleides. (A) Response from NII, $n=6$ ears, $n=5$ animals. (B) Response from NIII, $n=6$ ears, $n=6$ animals. Auditory responses were capped at $110 \mathrm{~dB}$ SPL. Median threshold responses are shown in bold. 
Table 2.1: Statistical comparisons (Mann-Whitney U-tests) of the audiograms from the two nerve branches NII and NIII in Morpho peleides.

\begin{tabular}{|c|c|c|c|c|c|c|c|c|c|c|c|}
\hline \multicolumn{2}{|c|}{$\begin{array}{l}\text { Frequency } \\
\text { at lowest } \\
\text { threshold } \\
(\mathrm{kHz})\end{array}$} & \multicolumn{2}{|c|}{$\begin{array}{l}\text { Threshold } \\
\text { at best } \\
\text { frequency } \\
\text { (dB SPL) }\end{array}$} & \multicolumn{2}{|c|}{$\begin{array}{l}\text { Bandwidth at } \\
10 \mathrm{~dB} \text { above } \\
\text { lowest } \\
\text { threshold } \\
(\mathrm{kHz})\end{array}$} & \multicolumn{2}{|c|}{$\begin{array}{l}\text { Area under } \\
70 \text { dB SPL } \\
\text { (arbitrary } \\
\text { units) }\end{array}$} & \multicolumn{2}{|c|}{$\begin{array}{l}\text { Area under } \\
80 \text { dB SPL } \\
\text { (arbitrary } \\
\text { units) }\end{array}$} & \multicolumn{2}{|c|}{$\begin{array}{l}\text { Area under } \\
100 \text { dB SPL } \\
\text { (arbitrary } \\
\text { units) }\end{array}$} \\
\hline NII & NIII & NII & NIII & NII & NIII & NII & NIII & NII & NIII & NII & NIII \\
\hline 1 & 2 & 56 & 54 & 1 & 2.1 & 49 & 160 & 67 & 100 & 259 & 312 \\
\hline 2 & 2 & 64 & 50 & 5.6 & 1.8 & 57 & 176 & 68 & 96 & 294 & 352 \\
\hline 3 & 2 & 55 & 52 & 3 & 2.5 & 173 & 214 & 97 & 109 & 363 & 423 \\
\hline 3 & 3 & 64 & 63 & 4.3 & 4.3 & 38 & 64 & 56 & 75 & 298 & 307 \\
\hline 2 & 3 & 64 & 58 & 6.5 & 4 & 51 & 132 & 79 & 98 & 303 & 338 \\
\hline 2 & 2 & 60 & 50 & 2.7 & 1.6 & 59 & 184 & 55 & 96 & 281 & 328 \\
\hline \multicolumn{2}{|c|}{$\begin{array}{c}\text { P-value }= \\
0.8103\end{array}$} & \multicolumn{2}{|c|}{$\begin{array}{c}\text { P-value }= \\
0.0455^{*}\end{array}$} & \multicolumn{2}{|c|}{$\begin{array}{c}\text { P-value }= \\
0.2627\end{array}$} & \multicolumn{2}{|c|}{$\begin{array}{c}\text { P-value }= \\
0.0203 *\end{array}$} & \multicolumn{2}{|c|}{$\begin{array}{c}\text { P-value }= \\
0.0308^{*}\end{array}$} & \multicolumn{2}{|c|}{$\begin{array}{c}\mathrm{P} \text {-value }= \\
0.0455^{*}\end{array}$} \\
\hline
\end{tabular}

*Significant $\mathrm{P}$-values based on alpha $=0.05$ 


\section{Supra-threshold responses}

Similar frequency tuning in the nerve branches does not imply that the responses to supra-threshold stimuli are similar. To investigate this further, we recorded and measured compound action potentials to sound stimuli of increasing amplitude. A sound stimulus at threshold barely resulted in a detectable CAP, whereas a sound stimulus well above threshold resulted in a larger and longer CAP. We quantified these two properties (amplitude and duration) of the CAP by the amplitude of the first peak of the CAP, and the area of the CAP respectively (Fig 2.2). Since the audiograms showed that the nerve branches respond best to frequencies between 1 and $8 \mathrm{kHz}$, we explored the effect of stimulus amplitude within that frequency range $(1,2,3,4,6$, and $8 \mathrm{kHz})$. As expected, both NII and NIII responded to increasing sound amplitudes by increasing both the amplitude of the first peak and the area of the CAP (Fig 2.4) at all frequencies tested. The increase in the response parameters with increasing stimulus amplitude was not the same for all frequencies (Fig 2.4C-F, Fig 2.5C-F). For example, we observed that at 4 and 6 $\mathrm{kHz}$, the supra-threshold CAPs from NII were larger when compared to NIII (Fig 2.4). In contrast, at lower and higher frequencies, the supra-threshold CAPs from NIII were larger than those of NII. These results suggest that NIII is responding best to lower frequencies while NII is responding best to higher frequencies. 
NII

A

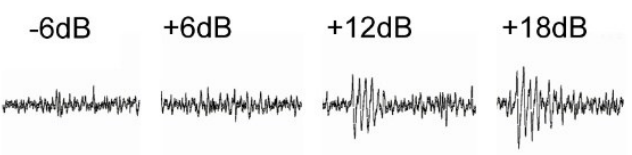

C
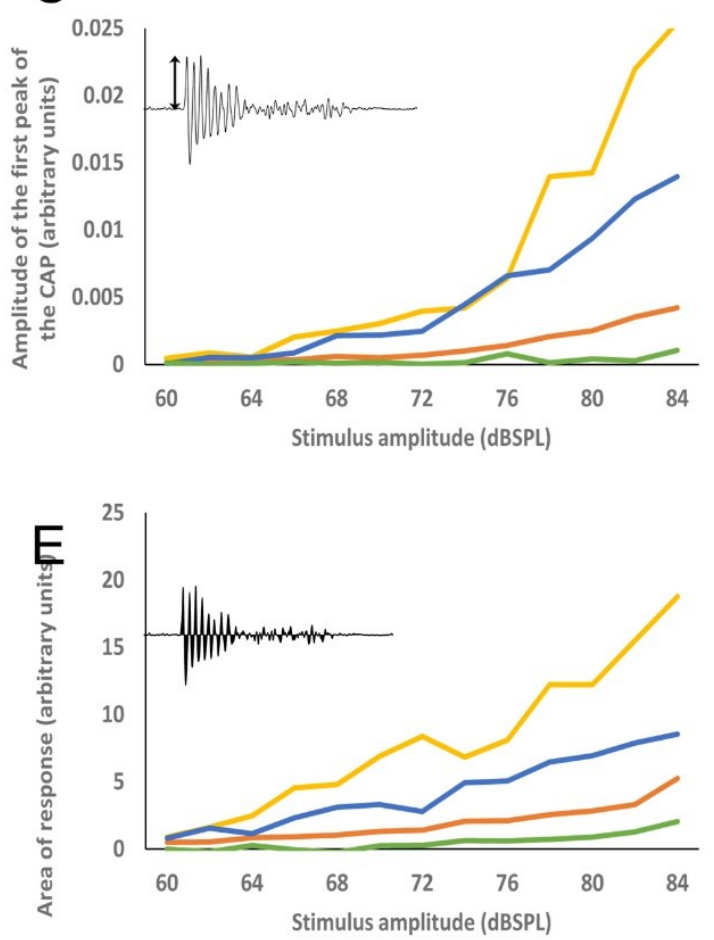

NIII

B

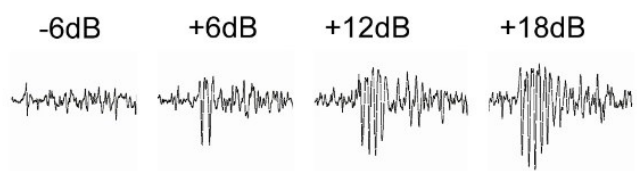

$\mathrm{D}$

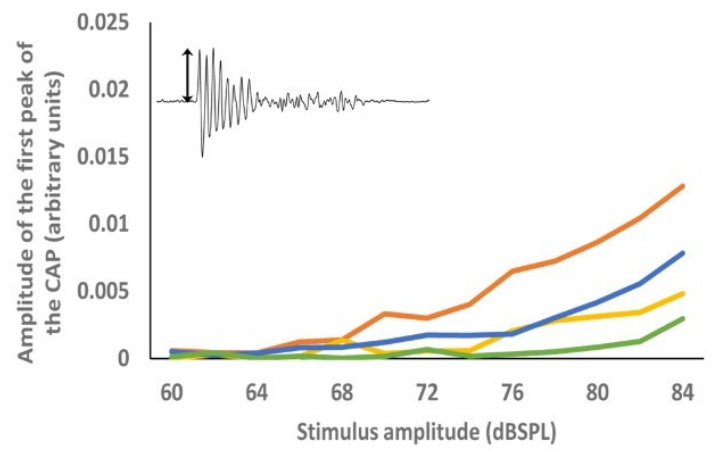

$\mathrm{F}$

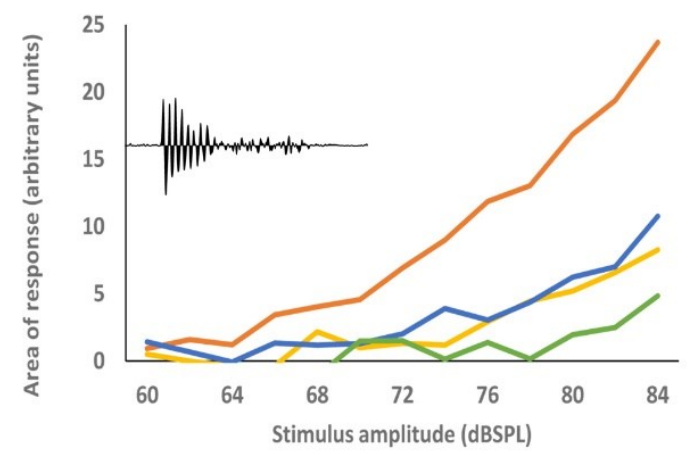

$-2 \mathrm{kHz}-4 \mathrm{kHz}-6 \mathrm{kHz}-8 \mathrm{kHz}$

Figure 2.4: Extracellular responses from NII and NIII in Morpho peleides. (A-B) Compound action potential (CAP) responses to $1 \mathrm{kHz}, 30 \mathrm{~ms}$ pulses ranging in amplitude from $6 \mathrm{~dB}$ below threshold to $18 \mathrm{~dB}$ above threshold. (C-F) Amplitude of the first peak of the CAP and area of the CAP, as a function of stimulus amplitude. 


\section{Vibration - Physiology results}

We compared our neurophysiological results of the two nerve branches to vibration properties of the membranes to which they attach. We found interesting corroboration between the two independent data sets as described below. Previous laser vibrometry measurements (Lucas et al., 2009) showed that the tympanal membrane vibrates in two distinct modes, depending on the frequency range. Specifically, Lucas et al. (2009) measured the vibration profile of the membrane at $2.5 \mathrm{kHz}$ and $6.5 \mathrm{kHz}$. At 2.5 $\mathrm{kHz}$, the vibration was mostly limited to the outer membrane, whereas at $6.5 \mathrm{kHz}$, the entire tympanal membrane vibrates, with the vibrations more concentrated on the inner membrane (Lucas et al., 2009) (Fig 2.5A-B). The attachment sites of the underlying chordotonal organs were found to correspond with the focal points of the two vibrational modes (Lucas et al., 2009) (Fig 2.1C). Since the membrane vibrations at $2.5 \mathrm{kHz}$ are limited to the outer membrane, we expect more cells in COIIIa and COIIIb to be activated compared to COII and hence the CAPs from NIII would be larger than those from NII. On the other hand, at $6.5 \mathrm{kHz}$, the inner membrane vibrates more and hence the response from NII would be expected to be larger than NIII. Our physiology results reflect these distinct vibrational modes; we found that at frequencies from 1 to $3 \mathrm{kHz}$, the supra-threshold response (as measured from both the amplitude and area of the CAPs) from NIII exceeded that of NII whereas from 4 to $6 \mathrm{kHz}$, the supra-threshold response from NII is larger (Fig 2.5C-F). 

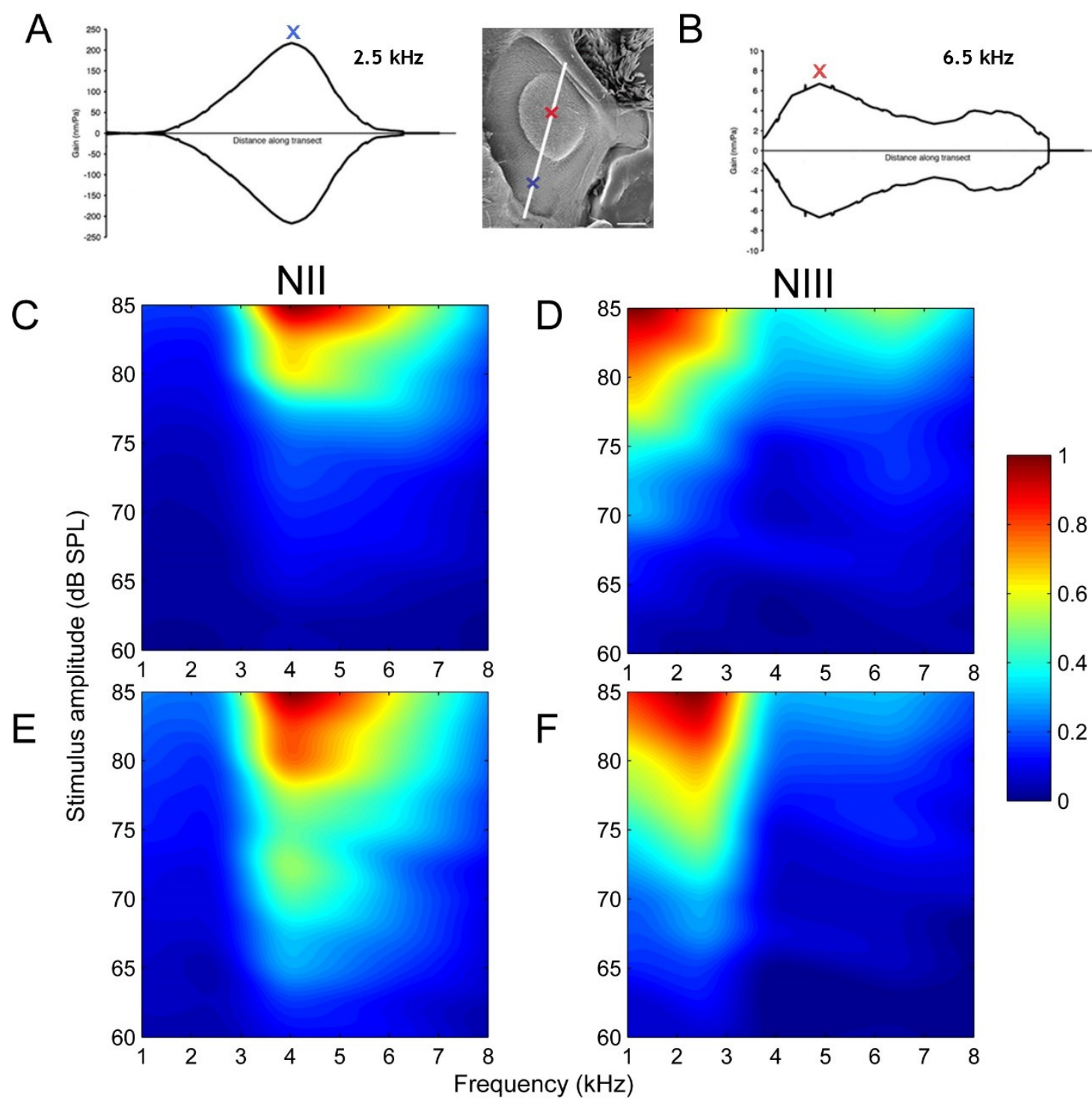

B

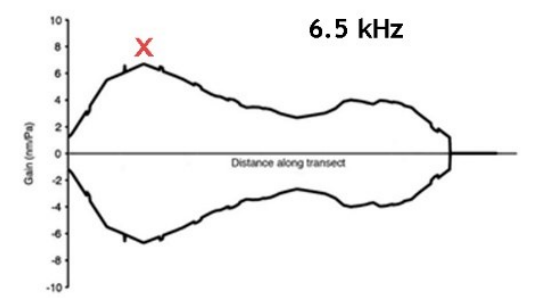




\section{Responses to avian flight sounds}

The hearing range of M. peleides overlaps with sounds produced by predators in its natural environment. In addition to responding to pure tones, the auditory nerve branches also responded to the passive flight sounds of birds such as blue jays (Fig 2.6, 2.7). Blue jay flight sounds were broadband (100 Hz-20 kHz) (Fig 2.6B-C, Fig 2.7B-C) and similar to the flight sounds of other insectivorous birds attacking tethered prey (Fournier, 2011; Fournier et al., 2013). Each down stroke of a blue jay wings, created a broadband pulse of sound that resulted in a CAP. The CAPs from both nerve branches increased in both peak amplitude ( $375 \%$ increase) and area ( $240 \%$ increase) as the playback volume of the flight sounds increased (Fig 2.6D-G, 2.7D-G). The recordings from NII (Fig 2.6) were consistently more "noisy" with more background activity and smaller CAPs compared to NIII (Fig 2.7). Additionally, NIII faithfully encoded the temporal characteristics of the flight sounds such as responding to each down stroke of

the bird's wings, whereas the activity from NII did not represent the down stroke pattern accurately. 


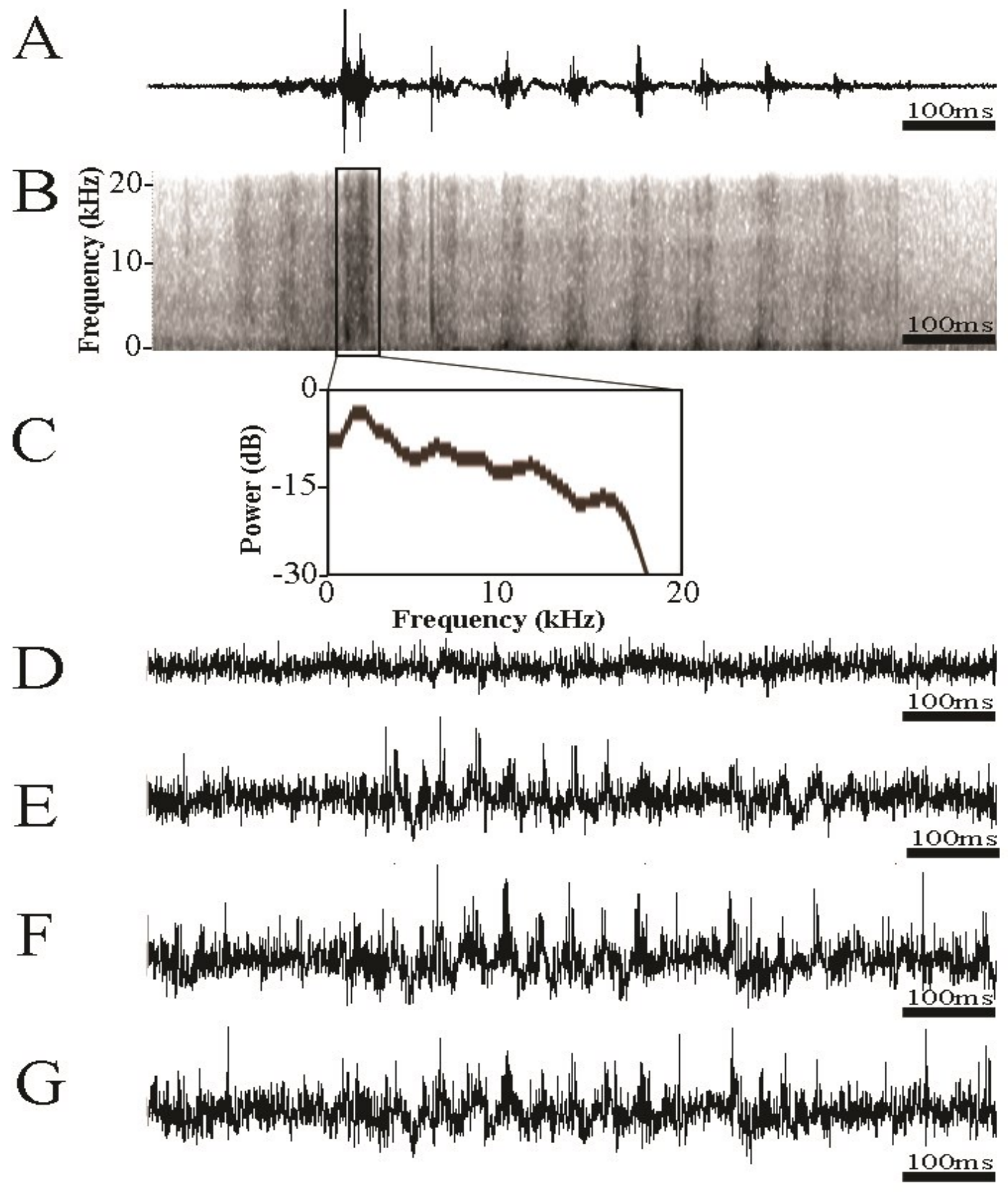

Figure 2.6: Auditory nerve responses of NII to blue jay (Cyanocitta cristata) flight sounds. (A) Bird flight sound waveform of blue jay as the bird flies away from a microphone. (B) Corresponding spectrogram. (C) Power spectrum of a single down stroke of the wings (inset in B). (D-G) Auditory nerve responses from NII at increasing levels of playback volume. 

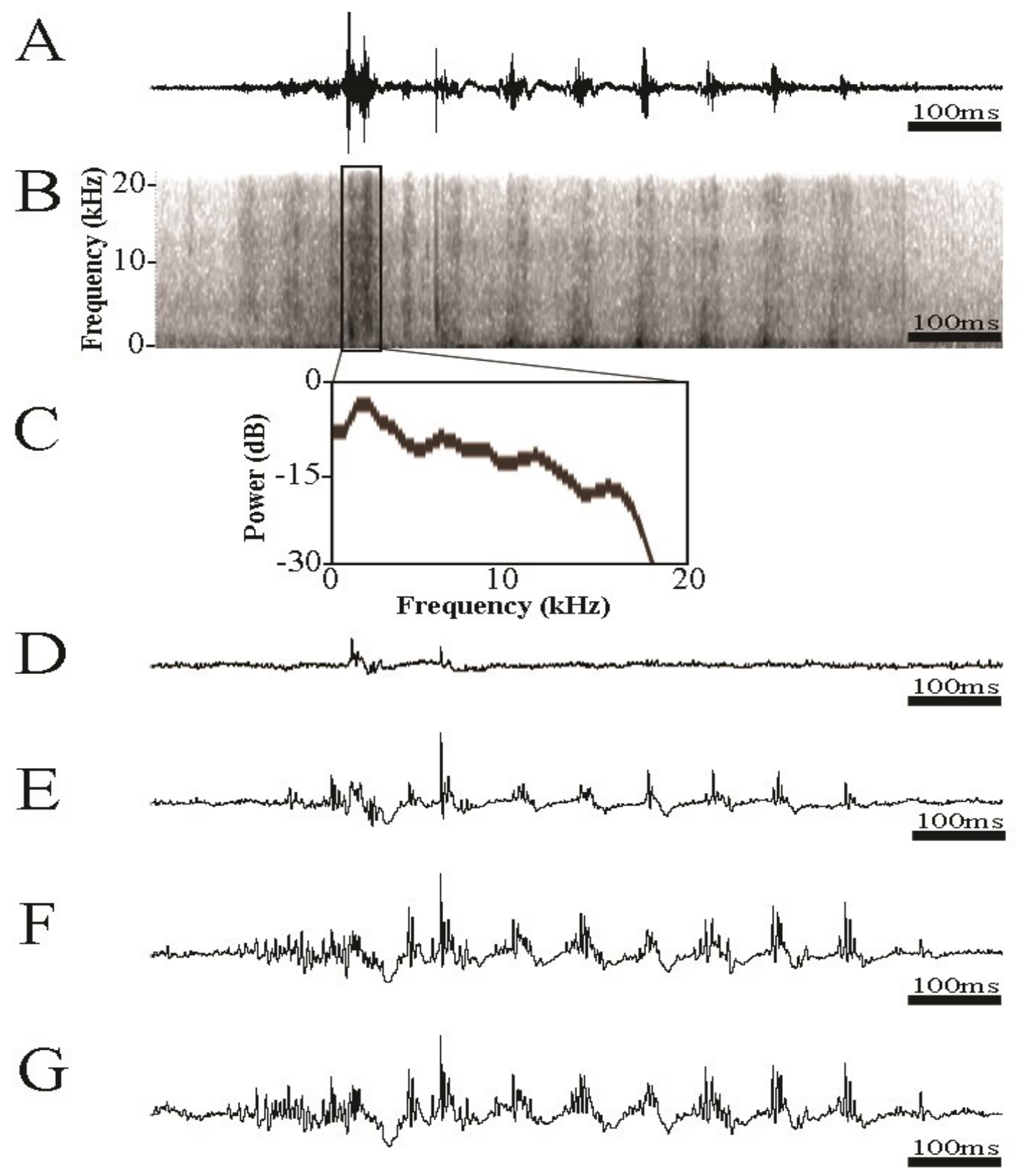

Figure 2.7: Auditory nerve responses of NIII to blue jay (Cyanocitta cristata) flight sounds. (A) Bird flight sound waveform of blue jay as the bird flies away from a microphone. (B) Corresponding spectrogram. (C) Power spectrum of a single down stroke of the wings (inset in B). (D-G) Auditory nerve responses from NIII at increasing levels of playback volume. 


\section{Responses to avian vocalizations}

Jacamar songs were lower in frequency $(2-5 \mathrm{kHz})($ Fig 2.8B-C) and longer in duration compared to blue jay flight sounds. Similar to the responses to the blue jay flight sounds, we recorded increases in CAP peak amplitude and area as the playback volume increased. Due to the longer $(\sim 200 \mathrm{~ms})$ stimulus durations of the jacamar vocalizations, the CAPs did not decay as rapidly (Fig 2.8). Despite being responsive to pure tone stimuli, NII consistently responded very weakly to jacamar vocalizations. We were unable to record clear CAPs from NII in response to jacamar sounds, perhaps owing to the low frequency nature $(2 \mathrm{kHz})$ of the vocalizations and the reduced sensitivity of NII at those frequencies. 


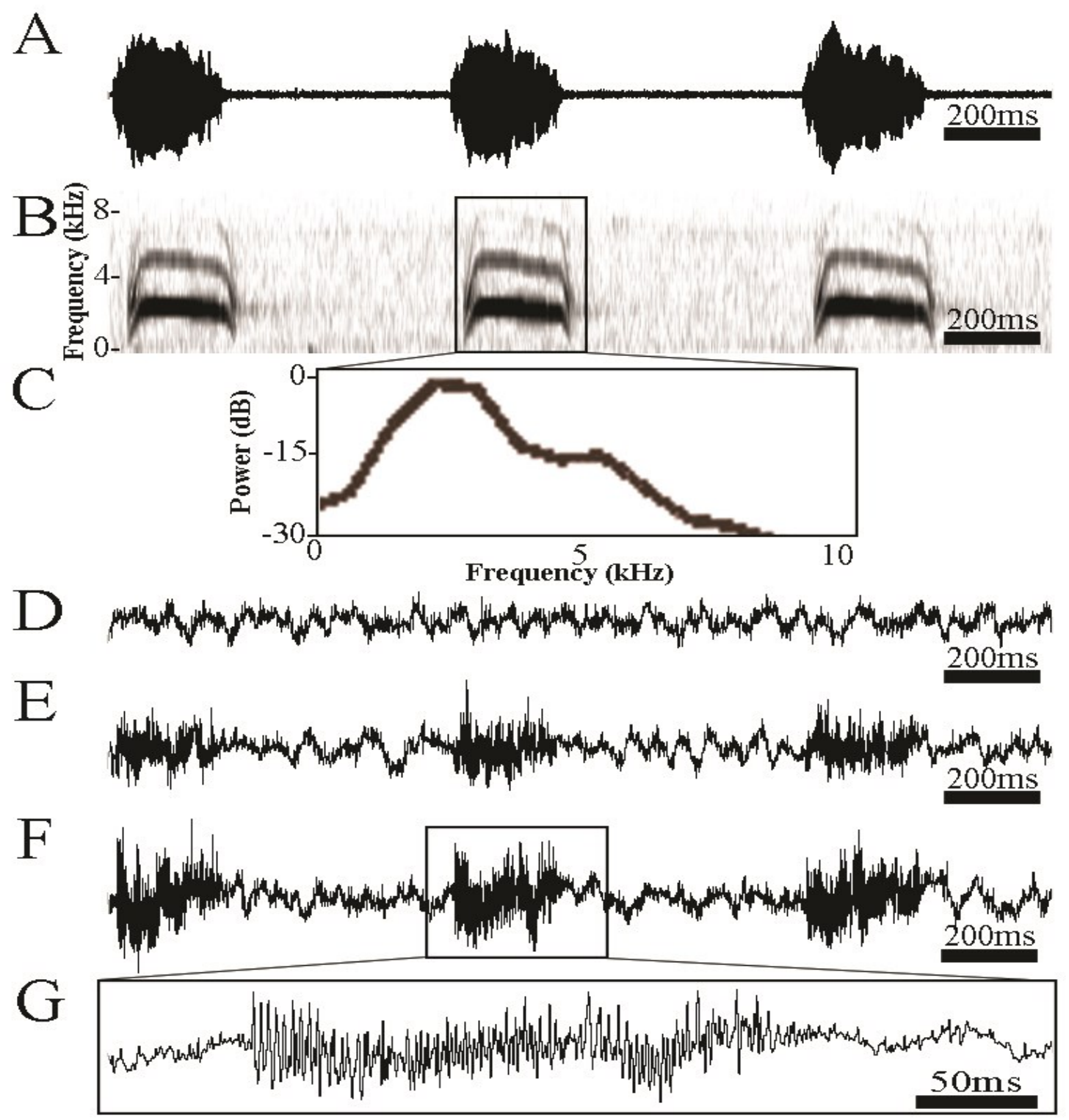

Figure 2.8: Auditory nerve responses of NIII to jacamar vocalizations (A) Song of the rufous-tailed jacamar (Galbula ruficauda). (B) Corresponding spectrogram. (C) Power spectrum of a single syllable (inset in B) (D-F) Auditory nerve responses from NIII at increasing levels of playback volume. (G) Close-up of response (inset in F) showing individual spikes of the CAP. 


\section{Discussion}

Multiple sensory cells are common in insect auditory systems and may function in frequency discrimination or to expand the dynamic range of hearing (Faure et al., 2008; Yager, 1999). In insect species that use tympanal ears primarily for predator detection, discriminating similar frequencies may be ecologically irrelevant. Such species, such as moths that detect the echolocation sounds of predatory bats, usually have simple broadly tuned ears (Mason and Faure, 2004). However, if the purpose of hearing is conspecific communication then subtle differences in signal characteristics need to be detected. This is important because such differences can encode information about the species or potential mate fitness levels (Bertram and Rook, 2011; Mason and Faure, 2004). In species such as crickets that detect both conspecific signals as well as predatory signals, a larger number of primary auditory afferents are allocated to discriminating the conspecific signals from the predatory signals (Pollack and Imaizumi, 1999). The function of hearing in diurnal butterflies is still unknown. This study examined the physiological response of the two auditory nerve branches, NII and NIII, in the Blue Morpho butterfly. We found both auditory branches in $M$. peleides to be similarly tuned and were sensitive to the same frequencies from 1-20 kHz (Fig 2.3).

Both nerve branches responded with compound action potentials (CAPs) (Fig 2.2). The CAP recorded from NII is the aggregate response of the cells in COII and similarly, the CAP recorded from NIII is the aggregate response of the cells in both COIIIa and COIIIb. Based on histological counts of scolopale caps and sensory cell bodies, it is estimated that COII contains 10-15 scolopidia, whereas COIIIa and COIIIb 
contain 10-12 and 15-20 scolopidia respectively (Lane et al., 2008; Lucas et al., 2009). Given the number of cells in each chordotonal organ, it is not yet possible to determine what fraction of cells is contributing to a given response. Our study focused instead on comparing the responses between both nerve branches However, if more cells are involved in the response of a single branch, or if cells fire more rapidly, the CAP would be larger and/or longer (Adam, 1977a; Adam, 1977b), and thus could provide a means of estimating cell recruitment. Usually, the first peak of the CAP is the largest because the cells are firing synchronously (Adam, 1977b). As the response progresses, the cells fire at varying rates and hence the subsequent peaks of the CAP diminish in size (Fig 2.2A) (Adam, 1977a; Adam, 1977b). By measuring the amplitude of the first peak of the CAP, we get a good estimate of the strength of the response (Pollack and Faulkes, 1998; Pollack and Imaizumi, 1999; Schul, 1999; Schul and Patterson, 2003). In some cases, the strength of the response might be represented in the duration of the CAP and to account for this, we also measured the CAP area, which accounts for both the amplitude and duration of the response (Imaizumi and Pollack, 1999; Pollack and Faulkes, 1998; Schul and Patterson, 2003).

We found that both the amplitude of the first peak and the area of the CAP of the response of both nerve branches increase with increasing intensity of the sound stimulus (Fig 2.4). This presumably occurs through additional recruiting of sensory receptors. Although both nerve branches have similar frequency tuning (Fig 2.3), the butterfly might be able to accomplish frequency discrimination by comparison of the activity of NII and NIII. This is because at frequencies below $4 \mathrm{kHz}$ and above $6 \mathrm{kHz}$, the supra- 
threshold response of NIII exceeds that of NII, but from 4-6 kHz, the supra-threshold response of NII exceeds that of NIII. This frequency dependent response is a reflection of the vibrational characteristics of the heterogeneous tympanal membrane. The complex topography of the tympanal membrane of $M$. peleides allows for two distinct vibrational modes (Lucas et al., 2009). At frequencies below $5 \mathrm{kHz}$, the vibrations of the tympanal membrane were focused on the posterior end of the outer membrane; the attachment site for COIIIa and COIIIb whereas at frequencies above $5 \mathrm{kHz}$, the entire membrane vibrated, but the inner membrane (attachment site for COII) vibrated more compared to the outer membrane (Lucas et al., 2009). The results from our physiology experiments correspond with the previously examined vibrational properties of the tympanal membrane of M. peleides (Lucas et al., 2009).

Currently, there is no data on the physiology of individual afferents of the auditory system in butterflies. Each chordotonal organ contains many cells (Lane et al., 2008; Lucas et al., 2009) and even though we have limited information on the tuning and intensity response of the organs, we do not know how single neurons respond to frequency and amplitude. The ability for frequency discrimination might be encoded in the intrinsic tuning of the sensory cells similar to the auditory system of the cicada (Fonseca et al., 2000). The projections that the sensory afferents make to interneurons in the central nervous system and the tuning of these interneurons also requires further studies. 
While many insects use sounds for conspecific communication, it is unlikely that M. peleides does. There are no accounts of M. peleides producing sound in the audible range and if they do produce sounds in the ultrasound, it does not appear that their ears are tuned to detect those sounds. Similar to M. peleides, most butterflies are mute. Certain species of Hamadryas butterflies are a notable exception however, since they produce short trains of intense double-component clicks, presumed to be part of their mating habits (Yack et al., 2000). Interestingly, the males of Hamadryas feronia produce sounds with peak frequencies at $14 \mathrm{kHz}$, but their ears are best tuned to frequencies of $1-2 \mathrm{kHz}$ (Yack et al., 2000). This frequency mismatch between the sounds produced and best sensitivity suggests a secondary function of hearing. Since the tuning of both $H$. feronia and M. peleides is similar, it is possible that their ears evolved in response to a common evolutionary pressure.

Nocturnal adult Lepidoptera are commonly preyed upon by nocturnal insectivorous bats. These bats use echolocation to both navigate and forage and as a result, many moths have evolved ears sensitive to the high-frequency sounds produced during echolocation. Butterflies however, are mostly diurnal and hence do not overlap temporally with nocturnal bats. In addition, like $M$. peleides, most butterfly ears are best tuned to frequencies of 1-6 kHz (Lane et al., 2008; Lucas et al., 2009; Mahony, 2006; Yack et al., 2007) whereas bat echolocation peak frequencies vary from 9-212 kHz (Ratcliffe et al., 2013). Nocturnal butterflies however, like butterflies in the genus Macrosoma (Yack et al., 2007) and Manataria (Rydell et al., 2003) are exposed to predatory bats and have been shown to respond to ultrasound. 
Many animals detect both active sounds produced by predators as well as sound cues produced by foraging predators as a result of their movement or interaction with the environment (Goerlitz and Siemers, 2007; Goerlitz et al., 2008). It has been proposed that butterfly ears function in detecting the flight sounds of attacking birds. Ribaric and Gogala (1996) first suggested that diurnal butterflies could be listening to songs of avian predators and Lane et al. (2008) later suggested that M. peleides could be listening to an approaching bird's flight sounds. Fournier et al. (2013) characterized the frequency and amplitude of bird flight sounds and provided physiological evidence that M. peleides could detect the flight sounds of approaching birds. Birds are a major predator of diurnal butterflies and hearing an approaching bird would favor butterflies possessing such ability. Further evidence that supports this hypothesis includes the overlap of bird flight sounds with the hearing range of M. peleides (Fournier et al., 2013; Lucas et al., 2009) and other diurnal butterflies (Mahony, 2006). Insectivorous birds prey on a variety of eared insects including butterflies (Pearce-Higgins, 2010; Pinheiro, 1996). Birds like rufous-tailed jacamars (Galbula ruficauda) and blue-crowned motmots (Momotus momota) capture and eat a lot of Morpho butterflies (Young, 1971; Young, 1972). Here, we provide evidence, at the sensory level, that M. peleides is able to detect the passive flight sounds of blue jays (Fig 2.6, 2.7) as well as the vocalizations produced by jacamars (Fig 2.8). In both cases, M. peleides encodes sound intensity increases by increasing the size of the CAP. If a bird is attacking a butterfly, the sound cues from the flapping flight get louder as the bird approaches the insect. As the sound gets louder, the CAP gets larger and this suggests that butterflies are able to judge distances to an approaching bird. By monitoring the change in the neural response over time, the butterfly could potentially 
estimate whether a bird is approaching (getting louder) or moving away (getting quieter). This potentially allows the butterfly to assess the threat level and behave accordingly. Neurophysiological latencies from our recordings were 5-10ms, which may allow sufficient time for evasive maneuvers, however, behavioural latencies were not tested.

Due to the variability in the attack scenarios (Fournier, 2011), it is difficult to know how close a bird needs to be before it could be detected by a butterfly. Based on the sensitivity of the butterfly's ear, and the loudness of bird flight sounds, Fournier et al. conservatively estimated that a butterfly would be able to detect a bird 2.5 meters away (Fournier et al., 2013). It is likely that insects use more than one sense to detect avian predators (Jabłoński and Lee, 2006; Santer et al., 2012) and hence might be able to detect birds farther away. By conducting behavioural experiments with unrestricted, freely behaving insects, we can explore the possibility of an anti-predator response that is correlated with the strength of the predation risk. Do butterflies exhibit different behavioural responses based on the perceived risk? This is observed in moths, which are sensitive to higher frequencies and are mostly listening to echolocating bats. If moths, detect a quiet sound from a bat, they simply fly in the opposite direction (negative phonotaxis) (Roeder, 1964). If however, they detect a loud sound, from a closer bat, they take more evasive manoeuvres (erratic flight/dives) (Roeder, 1964). In a similar manner, it would be interesting to explore whether butterflies utilize acoustic information to guide their behaviour. 
Butterflies exhibit remarkable adaptations to limit predation. Aposematism, disruptive colouration, mimicry, camouflage, eye spots, and erratic flight are just a few of the common defences in adult Lepidoptera. Our study provides further evidence that these insects may also be able to hear approaching predatory birds, expanding their repertoire of defences against predation. 


\section{Acknowledgements}

We thank Dick Burgess from London Pupae Supplies, for supplying the butterflies, Ed Bruggink (Carleton University) for help rearing the butterflies, and Dr. Jeff Dawson for technical help. 


\section{Funding}

This work was funded by a National Science and Engineering Research Council of Canada scholarship to A.M., as well as support from the Canadian Foundation for Innovation, the Ontario Innovation Trust, and the Natural Science and Engineering Research Council of Canada to J.E.Y. 
Section 3: General conclusion 
Animals from a wide variety of taxa are capable of recognizing cues indicating the presence of a predator (Goerlitz and Siemers, 2007; Lohrey et al., 2009), but this hypothesis has not been sufficiently explored for insects. Insect ears are traditionally thought of as dedicated to a specific task such as detecting a conspecific signal or detecting a bat echolocation call. Based on the results presented in this thesis, butterflies, and possibly other insects, may be using their hearing to detect the passive cues produced by predators such as birds. Birds prey upon a variety of insects and since the bird flight sounds are broadband, insects sensitive to low frequencies, such as butterflies, grasshoppers and cicadas, as well as insects sensitive to high frequencies, such as moths and mantids, would both be able to detect these sounds (Fournier et al., 2013). The detection of predatory cues might be a secondary function of hearing in many eared insects.

There are several cases in the literature where the primary function of hearing in an insect is for conspecific communication, but there is a mismatch between the dominant frequency of the call and the frequency of best hearing. In communication systems, to ensure effective transmission of a message, the receiver and the transmitter usually both evolve to emit and detect the same frequencies (Greenfield, 2002). Mismatches, thus suggest secondary functions of hearing besides conspecific communication. For example, some crickets (Cyphoderris monstrosa) call at $12 \mathrm{kHz}$ but their ears are most sensitive to $2 \mathrm{kHz}$ (Mason, 1991). The authors suggest that these crickets might be using their ears secondarily to detect incidental sounds produced by predators (Mason, 1991). Another example of a mismatch occurs in the blue cracker butterfly (Hamadryas feronia) where 
the best frequency measured from extracellular nerve recordings is $1.75 \mathrm{kHz}$ despite the mean peak frequency of the sounds produced being $14.4 \mathrm{kHz}$ (Yack et al., 2000). Once again, the authors suggest that this may function in predator detection (Yack et al., 2000).

Further evidence to support this hypothesis includes moths that have been removed from the selection pressure of bats either spatially or temporally and did not lose their ears completely. Some moths have retained their broad hearing and some have shifted their hearing away from the ultrasonic and into the sonic frequencies (Fullard, 1994; Soutar and Fullard, 2004; Surlykke et al., 1998). In these cases, it is possible that the moths may be secondarily using their ears for bird detection. There is some neurological and behavioural evidence that moths respond to the rustling sounds made by the cape bulbul (Pycnonotus capensis) as they pursued moths (Jacobs et al., 2008).

In fact, noctuid underwing moths physiologically responded to the flight sounds of an eastern phoebe (Sayornis phoebe) when tested in our laboratory (Fig 5.1). The moth was not only able to detect these sounds, but the auditory A cell fired consistently in response to the down strokes of the bird flight sounds. Additionally, the firing rate of the A cell increased as the playback volume increased. Although not tested behaviourally, the neural bursts from the A cell occurred with inter-burst intervals less than $2.6 \mathrm{~ms}$ which has been proposed to elicit evasive flight maneuvers (Roeder, 1964). Moths and butterflies have different auditory sensitivities and the fact that they both physiologically respond to bird flight sounds suggests that other eared insects might be responding as well. 


\section{Future directions}

Intracellular recordings, especially in cases like $M$. peleides, can help identify the characteristics of individual auditory afferents which might shed light on the adaptive significance of the complex membrane. It would be interesting to explore the hearing capabilities of butterflies that do not possess a well-defined inner membrane (tholus). According to Hall -who systematically examined the structure of VOs across several butterfly taxa-, there is considerable morphological variability within Nymphalidae butterflies (Hall, 2014). For example, Morpho polyphemus (Satyrinae) is within the same tribe (Morphini) as Morpho peleides, yet it has a homogenous tympanal membrane with no visible inner membrane. The absence of an inner membrane implies a lack of mechanical frequency discrimination, however, the adaptive significance remains unclear.

Behavioural experiments with unrestricted insects, can allow us to explore the possibility of an anti-predator response that is correlated with the strength of the predation risk. Do butterflies exhibit different behavioural responses based on the perceived risk? Moths, which are closely related to butterflies, are sensitive to higher frequencies $(>20 \mathrm{kHz})$ and are primarily listening to echolocation signals of predatory bats. It has been suggested that moths alter their behaviour depending on the volume of the detected sound with quiet sounds eliciting negative phonotaxis and louder sounds eliciting more drastic evasive maneuvers (Roeder, 1964). In a similar manner, we could test how butterflies respond behaviourally to approaching birds and whether butterflies use the loudness of a bird's sound to guide their behaviour. Extracellular field physiology 
rigs have been developed (Hall, 2014; Kostarakos and Römer, 2010; Rheinlaender and Romer, 1986) and are used to conduct physiology experiments in the field. Using such rigs with live birds instead of recordings can allow us to better estimate the detection distances under natural conditions.

Finally, it would also be interesting to explore whether there is an evolutionary arms race between birds and eared insects. Is there an evolutionary struggle between birds and eared insects where each evolves adaptations and counter-adaptations to each other? If insects evolved ears to take advantage of the passive cues generated by birds during flight, could birds have counter-evolved structural or behavioural adaptations rendering them acoustically cryptic? For example, feather and wing modifications in owls, perhaps combined with slow flight $(6-8 \mathrm{~m} / \mathrm{s})$, allow them to fly more quietly and thus reducing their detectability to prey (Sarradj et al., 2011). Perhaps there are behavioural adaptations that other birds exhibit which have not yet been explored. For example, do some birds glide, instead of flap, before capturing their prey? Gliding flight might be quieter than flapping flight, and it would not have a pulsed nature which potentially may allow birds to fly closer to their prey before being detected. Once again, behaviour studies with live birds and untethered insects will shed more light on this. Avian predation may have played an important role in the evolution of insect ears and like the moth-bat arms race, may prove to be one of neuroethology's exciting research areas. 


\section{Section 4: References}

Adam, L. (1977a). The oscillating summed action potential of an insect's auditory nerve (Locusta migratoria, Acrididae). I: Its original form and time constancy. Biol. Cyber. 26, 241-247.

Adam, L. (1977b). The oscillating summed action potential of an insect's auditory nerve (Locusta migratoria, Acrididae). II: Underlying spike pattern and causes of spike synchronization. Biol. Cyber. 28, 109-119.

Bennet-Clark, H. C. (1998). Size and scale effects as constraints in insect sound communication. Phil. Trans. R. Soc. Lond. B 353, 407-419.

Bertram, S. M. and Rook, V. (2011). Jamaican field cricket mate attraction signals provide age cues. Ethol. 117, 1050-1055.

Brumm, H. and Naguib, M. (2009). Environmental acoustics and the evolution of bird song. Adv. Study Behav. 40, 1-33.

Faure, P., Mason, A. and Yack, J. (2008). Invertebrate ears and hearing.pp. 1-8.

Fonseca, P. J., Münch, D. and Hennig, R. M. (2000). How cicadas interpret acoustic signals. Nature 405, 297-8.

Fournier, J.-P. (2011). If a bird flies in the forest, does anyone hear it?: Avian flight sound cues and hearing in Lepidoptera. M.Sc. Thesis, Biology, Carleton University, Ottawa, ON.

Fournier, J.-P., Dawson, J., Mikhail, A. and Yack, J. E. (2013). If a bird flies in the forest, does an insect hear it? Biol. Lett. 9, 20130319.

Fullard, J. H. (1994). Auditory habitat changes in noctuid moths endemic to a bat-free. J. Evol. Biol. 445, 435-445.

Fullard, J. and Yack, J. E. (1993). The evolutionary biology of insect hearing. TREE 8, $248-252$.

Fullard, J. H., ter Hofstede, H. M., Ratcliffe, J. M., Pollack, G. S., Brigidi, G. S., Tinghitella, R. M. and Zuk, M. (2010). Release from bats: genetic distance and sensoribehavioural regression in the Pacific field cricket, Teleogryllus oceanicus. Naturwissenschaften 97, 53-61.

Goerlitz, H. R. and Siemers, B. M. (2007). Sensory ecology of prey rustling sounds: acoustical features and their classification by wild Grey Mouse Lemurs. Funct. Ecol. 21, 143-153. 
Goerlitz, H. R., Greif, S. and Siemers, B. M. (2008). Cues for acoustic detection of prey: insect rustling sounds and the influence of walking substrate. J. Exp. Biol. 211, 2799-806.

Greenfield, M. (2002). Signalers and receivers: mechanisms and evolution of arthropod communication. New York: Oxford University Press.

Hall, L. (2014). Tympanal ears in nymphalidae butterflies: morphological diversity and tests on the function of hearing. M.Sc. Thesis, Biology, Carleton University, Ottawa, $\mathrm{ON}$.

Heikkilä, M., Kaila, L., Mutanen, M., Peña, C. and Wahlberg, N. (2012). Cretaceous origin and repeated tertiary diversification of the redefined butterflies. Proc. R. Soc. B. 279, 1093-9.

Hilty, S. (2003). Birds of Venezuela. 2nd ed. New Jersey: Princeton University Press.

Hoy, R. R. and Robert, D. (1996). Tympanal hearing in insects. Annu. Rev. Entomol. 41, 433-50.

Imaizumi, K. and Pollack, G. S. (1999). Neural coding of sound frequency by cricket auditory receptors. J. Neurosci. 19, 1508-16.

Jabłoński, P. G. and Lee, S. D. (2006). Effects of visual stimuli , substrate-borne vibrations and air current stimuli on escape reactions in insect prey of flush-pursuing birds and their implications for evolution of flush-pursuers. Behaviour 143, 303324.

Jacobs, D. S., Ratcliffe, J. M. and Fullard, J. H. (2008). Beware of bats, beware of birds: the auditory responses of eared moths to bat and bird predation. Behav. Ecol. 19, 1333-1342.

Kalmring, K. and Jatho, M. (1994). The effect of blocking inputs of the acoustic trachea on the frequency tuning of primary auditory receptors in two species of tettigoniids. J. Exp. Zool. 270, 360-371.

Knopp, M. C. N. and Krenn, H. W. (2003). Efficiency of fruit juice feeding in Morpho peleides (Nymphalidae, Lepidoptera). J. Insect. Behav. 16, 67-77.

Kostarakos, K. and Römer, H. (2010). Sound transmission and directional hearing in field crickets: neurophysiological studies outdoors. J. Comp. Physiol. A 196, 66981.

Kristensen, N. P. (2003). Lepidoptera, moths and butterflies. Berlin, Germany: Walter de Gruyter. 
Kristensen, N. P. and Skalski, A. (1998). Phylogeny and palaeontology. In Handbook of Zoology, bol. 4, Arthropoda: Insecta. Lepidoptera, Moths and Butterflies, vol. 1, Evolution, Systematics and Biogeography (ed. Kristensen, N. P.), pp. 7-25.

Lane, K., Lucas, K. M. and Yack, J. E. (2008). Hearing in a diurnal, mute butterfly, Morpho peleides (Papilionoidea, Nymphalidae). J. Comp. Neurol. 508, 677-86.

Lohrey, A. K., Clark, D. L., Gordon, S. D. and Uetz, G. W. (2009). Antipredator responses of wolf spiders (Araneae: Lycosidae) to sensory cues representing an avian predator. Anim. Behav. 77, 813-821.

Lucas, K. M. (2008). Hearing in two tropical butterflies, Morpho peleides and Caligo eurilochus (Nymphalidae: Satyrinae). M.Sc. Thesis, Biology, Carleton University, Ottawa, ON.

Lucas, K. M., Windmill, J. F. C., Robert, D. and Yack, J. E. (2009). Auditory mechanics and sensitivity in the tropical butterfly Morpho peleides (Papilionoidea, Nymphalidae). J. Exp. Biol. 212, 3533-41.

Mahony, S. (2006). Hearing in the speckled wood butterfly, Parage aegeria (Nymhalidae: Satyrinae). M.Sc. Thesis, Biology, Carleton University, Ottawa, ON.

Mason, A. C. (1991). Hearing in a primitive ensiferan: the auditory system of Cyphoderris monstrosa (Orthoptera: Haglidae). J. Comp. Physiol. A 168, 351-363.

Mason, A. C. and Faure, P. (2004). The physiology of insect auditory afferents. Microsc. Res. Tech. 63, 338-50.

Michelsen, A. (1971). The physiology of the locust ear, I. Frequency sensitivity of single cells in the isolated ear. Z. vergl. Physiol. 71, 49-62.

Michelsen, A. and Larsen, O. N. (1978). Biophysics of the ensiferan ear. I. Tympanal vibrations in bushcrickets (Tettifoniidae) studied with laser vibrometry. J. Comp. Physiol. A 123, 193-203.

Minet, J. and Surlykke, A. (2003). Lepidoptera, Moths and butterflies Vol 2: Morphology, physiology, and development. In (ed. Kristensen, N. P.), pp. 289-323. Berlin. New York: Walter de Gruyter.

Monge-Najera, J., Hernandez, F., Gonzalez, M. I., Soley, J., Araya, J. and Zolla, S. (1998). Spatial distribution, territoriality and sound production by tropical cryptic butterflies (Hamadryas, Lepidoptera : Nymphalidae): Implications for the "industrial melanism" debate. Rev. Biol. Trop. 46, 297-329. 
Nakano, R., Skals, N., Takanashi, T., Surlykke, A., Koike, T., Yoshida, K., Maruyama, H., Tatsuki, S. and Ishikawa, Y. (2008). Moths produce extremely quiet ultrasonic courtship songs by rubbing specialized scales. PNAS 105, 11812-7.

Oldfield, B. P. (1985). The tuning of auditory receptors in bushcrickets. Hear. Res. 17, 27-35.

Pearce-Higgins, J. (2010). Using diet to assess the sensitivity of northern and upland birds to climate change. Clim. Res. 45, 119-130.

Pinheiro, C. E. G. (1996). Palatablility and escaping ability in Neotropical butterflies: tests with wild kingbirds (Tyrannus melancholicus, Tyrannidae). Biol. J. Linn. Soc. 59, 351-365.

Pollack, G. and Faulkes, Z. (1998). Representation of behaviorally relevant sound frequencies by auditory receptors in the cricket Teleogryllus oceanicus. J. Exp. Biol. 201, 155-63.

Pollack, G. S. and Imaizumi, K. (1999). Neural analysis of sound frequency in insects. BioEssays 21, 295-303.

Ratcliffe, J. M., Elemans, C. P. H., Jakobsen, L. and Surlykke, A. (2013). How the bat got its buzz. Biol. Lett. 9, 20121031.

Rheinlaender, J. and Romer, H. (1986). Insect hearing in the field. J. Comp. Physiol. A 158, 647-651.

Ribaric, D. and Gogala, M. (1996). Acoustic behaviour of some butterfly species of the genus Erebia (Lepidoptera: Satyridae). Acta. Entomol. Slov. 4, 5-12.

Robert, D. and Göpfert, M. C. (2002). Novel schemes for hearing and orientation in insects. Curr. Opin. Neurobiol. 12, 715-20.

Roeder, K. D. (1964). Aspects of the noctuid tympanic nerve response having significance in the avoidance of bats. J. Comp. Physiol. A 10, 529-546.

Rydell, J., Kaerma, S., Hedelin, H. and Skals, N. (2003). Evasive response to ultrasound by the crepuscular butterfly Manataria maculata. Naturwissenschaften 90, 80-3.

Sakurai, R. (2011). Field observation of predation on adult lepidopterans by the tree sparrow Passer montanus saturatus. Entomol. Sci. 14, 162-165.

Santer, R. D., Rind, F. C. and Simmons, P. J. (2012). Predator versus prey: locust looming-detector neuron and behavioural responses to stimuli representing attacking bird predators. PLoS One 7, e50146. 
Sarradj, E., Fritzsche, C. and Geyer, T. (2011). Silent owl flight: Bird flyover noise measurements. AIAA J. 49, 769-779.

Schul, J. (1999). Neuronal basis for spectral song discrimination in the bushcricket Tettigonia cantans. J. Comp. Physiol. A 184, 457-461.

Schul, J. and Patterson, A. (2003). What determines the tuning of hearing organs and the frequency of calls? A comparative study in the katydid genus Neoconocephalus (Orthoptera, Tettigoniidae). J. Exp. Biol. 206, 141-152.

Soutar, A. and Fullard, J. H. (2004). Nocturnal anti-predator adaptations in eared and earless Nearctic Lepidoptera. Behav. Ecol. 15, 1016-1022.

Spangler, H. G. (1988). Moth hearing, defense, and communication. Annu. Rev. Entomol. 33, 59-81.

Stumpner, A. (1996). Tonotopic organization of the hearing organ in a bushcricket. Naturwissenschaften 83, 81-84.

Stumpner, A. and von Helversen, D. (2001). Evolution and function of auditory systems in insects. Naturwissenschaften 88, 159-170.

Surlykke, A. (1984). Hearing in notodontid moths: a tympanic organ with a single auditory neurone. J. Exp. Biol. 113, 323-335.

Surlykke, A., Skals, N., Rydell, J. and Svensson, M. (1998). Sonic hearing in a diurnal geometrid moth, Archiearis parthenias, temporally isolated from bats. Naturwissenschaften 85, 36-37.

Swihart, L. (1967). Hearing in butterflies (Nymphalidae: Heliconius, Ageronia). J. Insect. Behav. 13, 469-476.

Thiele, D. and Bailey, W. J. (1980). The function of sound in male spacing behaviour in bush-crickets (Tettigoniidae, Orthoptera). Aust. J. Ecol. 5, 275-286.

Vogel, R. (1912). Über die Chordotonalorgane in der Wurzel der Schmetterlingsflügel. Z. Wiss. Zool 100, 210-244.

Von Békésy, G. (1990). Experiments in hearing. J. Acoust. Soc. Am. 88, 2905.

Wagner, W. E. (1992). Deceptive or honest signalling of fighting ability? A test of alternative hypotheses for the function of changes in call dominant frequency by male cricket frogs. Anim. Behav. 44, 449-462. 
Wahlberg, N., Braby, M. F., Brower, A. V. Z., de Jong, R., Lee, M.-M., Nylin, S., Pierce, N. E., Sperling, F. a H., Vila, R., Warren, A. D., et al. (2005). Synergistic effects of combining morphological and molecular data in resolving the phylogeny of butterflies and skippers. Proc. R. Soc. B. 272, 1577-86.

Weir, J. T. and Wheatcroft, D. (2011). A latitudinal gradient in rates of evolution of avian syllable diversity and song length. Proc. R. Soc. B. 278, 1713-20.

Windmill, J. F. C., Göpfert, M. C. and Robert, D. (2005). Tympanal travelling waves in migratory locusts. J. Exp. Biol. 208, 157-68.

Wyttenbach, R., May, M. and Hoy, R. (1996). Categorical perception of sound frequency by crickets. Science 273, 1542-1544.

Yack, J. E. (2004). The structure and function of auditory chordotonal organs in insects. Microsc. Res. Tech. 63, 315-37.

Yack, J. E. and Dawson, J. W. (2007). Insect ears.pp. 1-18. Elsevier Ltd.

Yack, J. E. and Fullard, J. H. (1993). What is an insect ear? Ann. Entomol. Soc. Am. 86, $677-682$.

Yack, J. E. and Fullard, J. H. (2000). Ultrasonic hearing in nocturnal butterflies. Nature 403, 265-6.

Yack, J. E., Otero, L. D., Dawson, J. W., Surlykke, A. and Fullard, J. H. (2000). Sound production and hearing in the blue cracker butterfly Hamadryas feronia (Lepidoptera, Nymphalidae) from Venezuela. J. Exp. Biol. 203, 3689-702.

Yack, J. E., Kalko, E. K. V and Surlykke, A. (2007). Neuroethology of ultrasonic hearing in nocturnal butterflies (Hedyloidea). J. Comp. Physiol. A 193, 577-90.

Yager, D. D. (1999). Structure, development, and evolution of insect auditory systems. Microsc. Res. Tech. 47, 380-400.

Young, A. M. (1971). Wing coloration and reflectance in Morpho Butterflies as related to reproductive behavior and escape from avian predators. Oecologia 7, 209-222.

Young, A. M. (1972). Adaptive strategies of feeding and predator-avoidance in the larvae of neotropical butterfly, Morpho peleides limpida (Lepidoptera: Morphidae). J. NY. Entomol. Soc. 80, 66-82. 


\section{Section 5: Appendix}

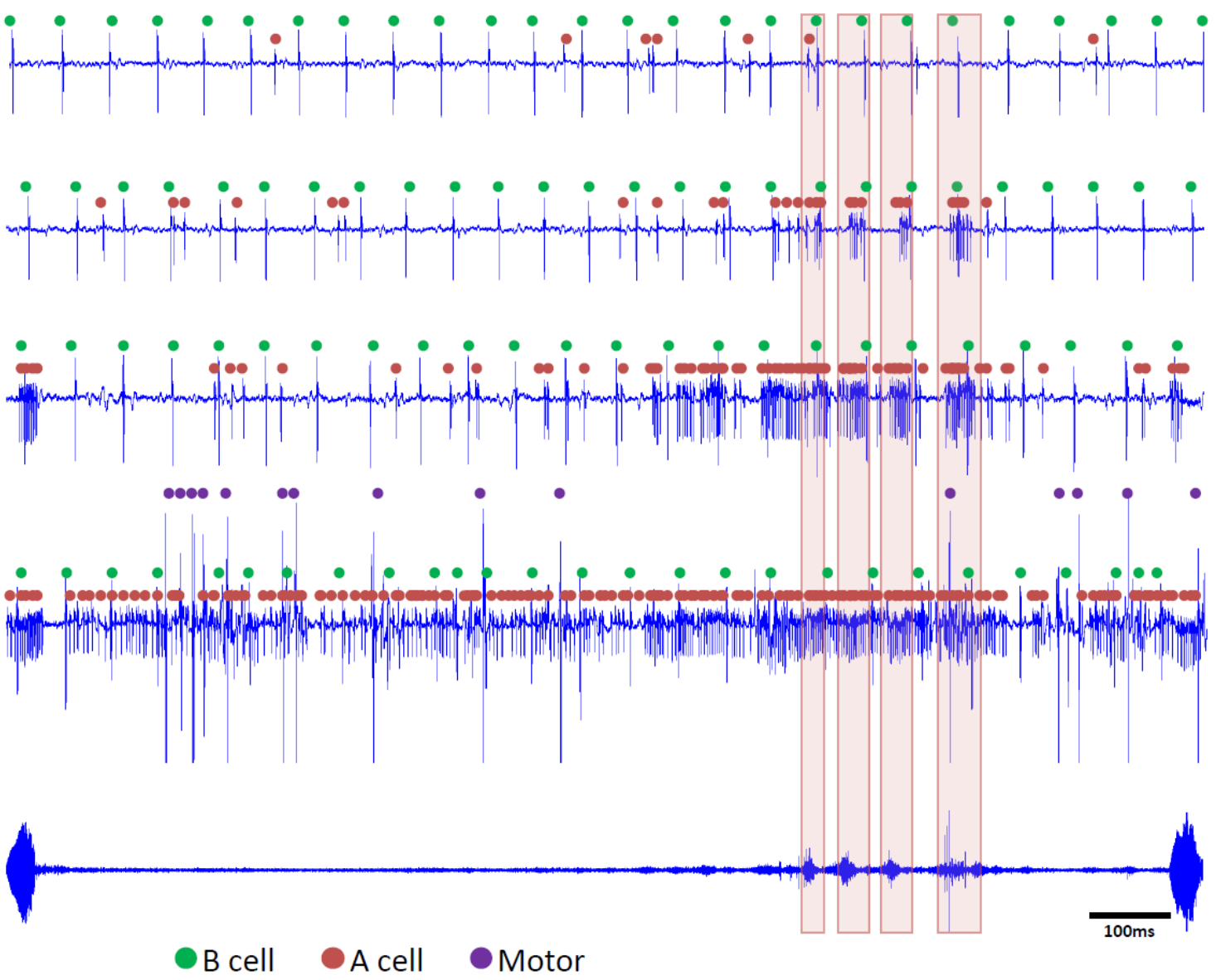

Figure 5.1: Neural response of an underwing moth (Noctuoidea) (top 4 panels) to various amplitudes of the broadband flight sounds of an eastern phoebe (Sayornis phoebe) (bottom panel). The shaded boxes represent the down strokes of the bird's flight as determined by synchronized video and audio recordings. 